\title{
Accumulation of Seminolipid in Sertoli Cells Is Associated with Increased Levels of Reactive Oxygen Species and Male Subfertility: Studies in Aging Arsa Null Male Mice
}

\author{
Kessiri Kongmanas ${ }^{1,2,3,4,+}+\mathbb{D}$, Arpornrad Saewu 1,+(D), Wongsakorn Kiattiburut ${ }^{1}$, Mark A Baker ${ }^{5}$, Kym F Faull ${ }^{6}$, \\ Dylan Burger 1,7 (D) and Nongnuj Tanphaichitr $1,2,8, * \mathbb{D}$
}

1 Chronic Disease Program, Ottawa Hospital Research Institute, Ottawa, ON K1H 8L6, Canada; kessiri.kon@mahidol.ac.th (K.K.); arpornrad@hotmail.com (A.S.); wkiattib@uwo.ca (W.K.); dburger@uottawa.ca (D.B.)

2 Department of Biochemistry, Microbiology, Immunology, Faculty of Medicine, University of Ottawa, Ottawa, ON K1H 8M5, Canada

3 Division of Dengue Hemorrhagic Fever Research/Siriraj Center of Research Excellence in Dengue and Emerging Pathogens, Faculty of Medicine Siriraj Hospital, Mahidol University, Bangkok 10700, Thailand

4 Siriraj Metabolomics and Phenomics Center, Faculty of Medicine Siriraj Hospital, Mahidol University, Bangkok 10700, Thailand

5 Department of Biological Science, University of Newcastle, Callaghan, NSW 2308, Australia; Mark.Baker@newcastle.edu.au

check for

updates

Citation: Kongmanas, K.; Saewu, A.; Kiattiburut, W.; Baker, M.A; Faull, K.F; Burger, D.; Tanphaichitr, N. Accumulation of Seminolipid in Sertoli Cells Is Associated with Increased Levels of Reactive Oxygen Species and Male Subfertility: Studies in Aging Arsa Null Male Mice. Antioxidants 2021, 10, 912. https:// doi.org/10.3390/antiox10060912

Academic Editors: Branca M. Silva and Pedro F. Oliveira

Received: 25 April 2021

Accepted: 1 June 2021

Published: 4 June 2021

Publisher's Note: MDPI stays neutral with regard to jurisdictional claims in published maps and institutional affiliations.

Copyright: (C) 2021 by the authors Licensee MDPI, Basel, Switzerland. This article is an open access article distributed under the terms and conditions of the Creative Commons Attribution (CC BY) license (https:/ / creativecommons.org/licenses/by/ $4.0 /)$.
6 Pasarow Mass Spectrometry Laboratory, University of California, Los Angeles, CA 90024, USA; faull@chem.ucla.edu

7 Department of Cellular and Molecular Medicine, Faculty of Medicine, University of Ottawa, Ottawa, ON K1H 8M5, Canada

8 Department of Obstetrics \& Gynecology, Faculty of Medicine, University of Ottawa, Ottawa, ON K1H 8L6, Canada

* Correspondence: ntanphaichitr@ohri.ca; Tel.: +1-(613)-737-8899 (ext. 72793); Fax: +1-(613)-739-6968

+ Sharing first authorship.

Abstract: Seminolipid (also known as sulfogalactosylglycerolipid-SGG), present selectively in male germ cells, plays important roles in spermatogenesis and sperm-egg interaction. The proper degradation of SGG in apoptotic germ cells is also as important. Sertoli cells first phagocytose apoptotic germ cells, then Sertoli lysosomal arylsulfatase A (ARSA) desulfates SGG, the first step of SGG degradation. We have reported that aging male $\mathrm{Arsa}^{-/-}$mice become subfertile with SGG accumulation in Sertoli cell lysosomes, typical of a lysosomal storage disorder (LSD). Since reactive oxygen species (ROS) levels are increased in other glycolipid-accumulated LSDs, we quantified ROS in Arsa-/- Sertoli cells. Our analyses indicated increases in superoxide and $\mathrm{H}_{2} \mathrm{O}_{2}$ in $A r s a^{-/}$Sertoli cells with elevated apoptosis rates, relative to WT counterparts. Excess $\mathrm{H}_{2} \mathrm{O}_{2}$ from Arsa ${ }^{-/}$- Sertoli cells could travel into testicular germ cells (TGCs) to induce ROS production. Our results indeed indicated higher superoxide levels in $\mathrm{Arsa}^{-/-}$TGCs, compared with WT TGCs. Increased ROS levels in Arsa ${ }^{-/-}$ Sertoli cells and TGCs likely caused the decrease in spermatogenesis and increased the abnormal sperm population in aging $\mathrm{Arsa}^{-1-}$ mice, including the $50 \%$ decrease in sperm SGG with egg binding ability. In summary, our study indicated that increased ROS production was the mechanism through which subfertility manifested following SGG accumulation in Sertoli cells.

Keywords: male fertility; reactive oxygen species; oxidative stress; sperm quality; testicular germ cells; sulfogalactosylglycerolipid; seminolipid; arylsulfatase A; Sertoli cells; storage diseases

\section{Introduction}

Sulfogalactosylglycerolipid (SGG) is expressed selectively in mammalian male germ cells at a substantial level [1,2]. SGG is a structural analogue of sulfogalactosylceramide (SGC, also known as sulfatide), present in oligodendrocytes in the brain and epithelial 
cells of various tissues. Although the two sulfoglycolipids have different backbone neutral lipids, palmitylpalmitoylglycerol (PPG) for SGG and ceramide for SGC, they share the same biosynthesis pathway. Namely, ceramide galactosyltransferase (CGT) galactosylates PPG and ceramide to generate galactosylglycerolipid (GG) and galactosylceramide (GC), which are then sulfated by cerebroside sulfotransferase (CST) to form SGG and SGC, respectively [1]. Mice with global genetic deletion of $\mathrm{Cgt}$ or Cst show tremor and ataxia due to the myelin sheath dysfunction [3,4]. Significantly, $\mathrm{Cgt}^{-/-}$and $\mathrm{Cst}^{-/-}$male mice are infertile [4,5]. In WT mice, SGG is first synthesized in primary spermatocytes [1], and in these two knockout $(\mathrm{KO})$ mice, spermatogenesis is halted at this germ cell stage $[4,5]$. The results indicate that SGG is indispensable in this process. Furthermore, our accumulated studies reveal the significance of sperm SGG in fertilization [6,7]. SGG is also a critical component in the formation of sperm lipid raft membranes [8,9], which are the interaction platforms between sperm and the egg extracellular matrix, the zona pellucida (ZP) $[8,10]$. Additionally, SGG possesses inherent affinity to the ZP $[6,8]$.

SGG also shares the same degradation pathway with SGC, involving two lysosomal enzymes (and their co-enzymes), i.e., arylsulfatase A (ARSA) (and saposin B) to produce GG and GC, and galactosyl ceramidase (GALC) (and saposin A) to generate their corresponding backbone neutral lipids, PPG and ceramide, respectively [1]. This degradation pathway was first discovered for SGC due to the natural mutations in humans of ARSA and GALC, which lead to the lysosomal accumulation of SGC and GC, respectively, and subsequent lysosomal distension, as well as cytotoxicity. These lysosomal storage disorders (LSDs) are termed metachromatic leukodystrophy (MLD) and globoid cell leukodystrophy (also known as Krabbe disease) for the deficiency of ARSA and GALC activities, respectively. Individuals with MLD or Krabbe disease suffer severe neurological and motor neuron disorders caused by the demyelination of their neuron cells, and they usually die young [11,12]. Similarly, Galc mutant mice (also known as twitcher Twi/Twi) exhibit body tremors, and for most strains, they die young. Only one twitcher mouse strain can live up to 50 days [13], slightly beyond the first spermatogenesis wave. In these twitcher mice, GG is accumulated in Sertoli cells, implicating the role of GALC in degalactosylating GG to PPG. These twitcher mice are infertile, owing to the production of abnormal sperm and architectural impairment of the epididymis $[14,15]$.

Mice with global genetic deletion of Arsa were generated for studies of MLD molecular mechanisms [16]. Arsa null mice exhibit SGC accumulation in the brain as expected [1]. However, they have mild symptoms of MLD [16] and they can live at least to 18 months of age (our unpublished observation). We have previously demonstrated by mass spectrometrybased lipidomic analyses that the levels of SGG are increased in the testis of Arsa null mice, as compared with the levels in age-matched wild types. Immunofluorescence studies indicate that this increase is likely attributed to SGG accumulation in Arsa null Sertoli cells. Electron microscopy further reveals that lysosomes in Sertoli cells of aging Arsa ${ }^{-/-}$mice are much distended, with numerous lipid droplets present in these cells, all characteristics typical of an LSD [17]. Aging $\mathrm{Arsa}^{-/-}$mice (more than 5 months of age) are subfertile with significant issues in spermatogenesis, an increase in apoptotic TGCs in the seminiferous tubules, abnormal sloughing of TGCs into the seminiferous tubule and epididymal lumen, abnormal morphology of sperm produced and a minimal ability of epididymal sperm to fertilize eggs in vitro [17]. Since Sertoli cells are sustentacular cells, with essential roles in supporting spermatogenesis [1], the abnormalities in the spermatogenesis events mentioned above are likely the consequences of dysfunctionality of Sertoli cells in $\mathrm{Arsa}^{-/-}$ mice. The primary objective of this report was to discern the molecular mechanisms, which caused these dysfunctions. Based on previous reports in a number of LSDs that oxidative stress is the mechanism of LSD-induced cytotoxicity [18], our study was targeted towards measuring ROS in Sertoli and TGCs of $\mathrm{Arsa}^{-/-}$mice. With the recently available method to isolate Sertoli cells from adult mice with high purity [19], we also confirmed the accumulation of SGG in these cells from $\mathrm{Arsa}^{-/-}$mice by quantitative electrospray ionization-tandem mass spectrometry (ESI-MS/MS). 


\section{Materials and Methods}

\subsection{Mice}

$\mathrm{Arsa}^{-/-}$mice originally created by Hess et al. [16] were rederived by Dr. Tony Rupar at the Animal Care and Veterinary Services, University of Western Ontario, London, Ontario, Canada by breeding them into the C57BL/ 6 background. A pair of male and female $\mathrm{Arsa}^{-/}$mice and wild type C57BL/6 mice were generously provided to us. Breeding between $\mathrm{Arsa}^{-1-}$ males and $\mathrm{Arsa}^{-/}$females was performed to maintain the colony and to supply $\mathrm{Arsa}^{-/-}$males for this study. Wild type C57BL/6 males were either obtained from in-house breeding or purchased from Charles River (Senneville, QC, Canada). All mice were kept in a temperature-controlled room with 14-h light and 10-h dark photoperiod and were fed ad libitum with Purina rodent chow and water. The use of mice (protocol 2568) was approved by the University of Ottawa Animal Care Committee, which endorses the use of ARRIVE checklists and guideline.

\subsection{Isolation of Tissues and Cells}

Testes and caput and cauda epididymides were removed free from the surrounding fat pad and/or blood vessels from male mice sacrificed by cervical dislocation. Caput and cauda epididymides were used directly for incubation with dihydroethidium (DHE, see below). In another set of experiments, sperm were collected from the cauda epididymis for further processing (see below).

\subsubsection{Seminiferous Tubules and Sertoli cells}

To prepare seminiferous tubules, decapsulated testes were subjected to collagenase digestion. Details of enzymatic digestions were as previously described [19]. The seminiferous tubules obtained after collagenase digestion were either used directly for DHE incubation (see below) or further subjected to a series of enzyme digestions [19], which finally yielded loose cells comprising Sertoli cells, TGCs, heads and tails of elongated spermatids and testicular sperm as well as tubule remnants (incompletely digested by the enzymes). A primary culture of Sertoli cells was then prepared from this cell mixture according to our described method [19].

\subsubsection{Testicular Germ Cells}

TGCs were prepared by incubating $\left(15 \mathrm{~min}, 35^{\circ} \mathrm{C}\right)$ seminiferous tubules (isolated as described above from two testes) with $3 \mathrm{~mL}$ of $0.25 \mathrm{mg} / \mathrm{mL}$ trypsin and $10 \mu \mathrm{g} / \mathrm{mL}$ DNase I in DMEM/F12 (made without phenol red) in a shaking (150 rpm) water bath. During the last $3 \mathrm{~min}$, the suspension was gently pipetted up and down with a transfer pipet to accelerate the dispersion of the tubules. After stopping the trypsin reaction with $0.25 \mathrm{mg} / \mathrm{mL}$ soybean trypsin inhibitor (STI), the suspension was centrifuged $(800 \times g, 3 \mathrm{~min}$, room temperature (RT)) to pellet the dispersed cells and undigested tubule fragments, which were washed once by centrifugation in DMEM/F12. The suspension was then incubated ( $20 \mathrm{~min}, 35^{\circ} \mathrm{C}$ ) with $3 \mathrm{~mL}$ of $1 \mathrm{mg} / \mathrm{mL}$ collagenase, $2 \mathrm{mg} / \mathrm{mL}$ hyaluronidase, $10 \mu \mathrm{g} / \mathrm{mL}$ DNase I, $0.25 \mathrm{mg} / \mathrm{mL}$ STI in DMEM/F12 in the shaking water bath to further dissociate the remaining undigested tubules. At the end of the incubation, the dissociated cells and tubule remnants were washed twice by centrifugation $\left(800 \times g, 3 \mathrm{~min}, 28{ }^{\circ} \mathrm{C}\right)$ with DMEM/F12 or another buffer solution specific for the downstream experiment. The tubule remnants were then removed by passing the cell suspension through a $100 \mu \mathrm{m}$ cell strainer, and the filtrate containing loose cells was subjected to cell counting. The majority (95-97\%) of intact cells in the filtrate were TGCs, with only 3-5\% being Sertoli cells. This cell suspension was therefore used to represent TGCs in immunoblotting and DHE experiments (see below). 


\subsection{Collection of Caudal Epididymal and Vas Deferens Sperm and Their Separation into Percoll Gradient-Interfaced and Percoll-Gradient-Pelleted Populations}

Sperm were collected as milk-like fluids from the cauda epididymis and vas deferens into KRB-HEPES as previously described [20]. The sperm fluid collected from either 5 or 8-month old WT and Arsa null mice were subjected to Percoll gradient centrifugation (1 mouse/gradient for both ages of WT mice and 5-month-old Arsa null mice; 2-3 mice/gradient for 8-month-old Arsa null mice). The sperm fluid was resuspended in $2 \mathrm{~mL}$ of KRB-HEPES and then subjected to centrifugation $\left(650 \times g, 30 \mathrm{~min}, 28^{\circ} \mathrm{C}\right)$ through a Percoll gradient (35\% and 70\% solution made in KRB-HEPES, $2 \mathrm{~mL}$ each), which separated sperm into the Percoll-gradient interfaced and Percoll-gradient pelleted populations. These two sperm populations were washed once in KRB-HEPES by centrifugation $\left(500 \times g, 5 \mathrm{~min}, 28^{\circ} \mathrm{C}\right)$ and then applied onto a slide for staining with Diff-Quik solution (Siemens Healthcare Limited, Oakville, ON, Canada) following the manufacturer's instruction. The morphology of stained sperm was viewed under a Zeiss Axioscope microscope. Percoll-gradient centrifuged (PGC) sperm (the pellet fraction) were also used for sulfolipid quantification (see below).

\subsection{Immunofluorescence of Sertoli Cells for ARSA, LAMP1, Saposin B, and SGG}

Primary cultures of Sertoli cells in an ibidi high-walled $\mu$-Dish 35-mm plate dish (ibidi USA, Inc., Fitchburg, WI, USA) with at least 70\% confluence were used for immunofluorescence to co-localize ARSA, saposin B or SGG with LAMP1. Primary antibodies and corresponding secondary antibodies are as described in Supplemental Table S1. Sertoli cell cultures were first washed with PBS, which was used for washing the cultures in between all treatment steps and also for the dilution of all reagents. They were then fixed ( $15 \mathrm{~min}$, RT) with $4 \%$ paraformaldehyde (PFA) and permeabilized (5 min, RT) with $0.1 \%$ Triton $\mathrm{X}-100$. Non-specific binding was blocked $(1 \mathrm{~h}, \mathrm{RT})$ using the blocking solution specific for each secondary antibody (Supplemental Table S1). The culture was subsequently incubated $(1 \mathrm{~h}, \mathrm{RT})$ with the primary antibody and the corresponding secondary antibody ( $1 \mathrm{~h}, \mathrm{RT})$. In all co-localization pairs, the incubation with anti-LAMP1 and its secondary antibody was performed after the incubation with anti-ARSA, anti-saposin B or anti-SGG and its secondary antibody. Sertoli cell cultures incubated with isotype IgG or IgM control, in place of the primary antibody, served as negative controls. After completing immunofluorescence steps, the culture was incubated with Hoechst $33258(5 \mu \mathrm{g} / \mathrm{mL}$, Molecular probes: cat. no. H-2491). The Sertoli cell cultures were then viewed under a Zeiss Axio epifluorescence microscope using the rhodamine filter for LAMP1 detection, the fluorescein filter for other antigens and the Hoechst filter for the Hoechst dye. Images of the three filters were merged for presentation.

\subsection{Immunoblotting for ARSA}

TGCs and Sertoli cells detached from the substratum by treatment with Accutase Cell Detachment Solution (BD Biosciences) were treated $\left(90{ }^{\circ} \mathrm{C}, 5 \mathrm{~min}\right.$ ) with $2 \%$ SDS in $0.0625 \mathrm{M}$ Tris- $\mathrm{HCl}, \mathrm{pH}$ 6.8. At the end of the treatment, particulates were removed from the treated cells by centrifugation $(14,000 \times g, 5 \mathrm{~min}, \mathrm{RT})$. Proteins in the supernatant were then quantified using the BCA Protein Assay Kit (Thermo Fisher Scientific, Waltham, MA, USA) and added with DTT to the final concentration of $100 \mathrm{mM}$. Proteins $(50 \mu \mathrm{g})$ were subjected to Laemmli SDS-PAGE (on a 10\% polyacrylamide gel) and the electrophoresed proteins were electro-transferred (100 V, 1 h) [21] onto a nitrocellulose membrane (BioRad Laboratories) for immunoblotting with anti-ARSA. The membrane was first blocked $(1 \mathrm{~h}, \mathrm{RT})$ for non-specific binding in 5\% nonfat skim milk in TBST $(10 \mathrm{mM}$ Tris- $\mathrm{HCl}$, $\mathrm{pH} 7.4,150 \mathrm{mM} \mathrm{NaCl}, 0.1 \%$ Tween 20$)$ and then incubated $\left(12 \mathrm{~h}, 4{ }^{\circ} \mathrm{C}\right)$ with anti-ARSA (MyBiosource, 1:1000 dilution in the blocking solution). This was followed by incubation $(1 \mathrm{~h}, \mathrm{RT})$ with the secondary antibody-HRP-conjugated rabbit anti-goat IgG antibody (BioRad, 1:3000 dilution in the blocking solution). In between incubation steps, the membrane was washed twice with TBST (10 min per wash, RT). The antigen-antibody complex 
was revealed by enhanced chemiluminescence on a GE Healthcare Amersham Hyperfilm (Thermo Fisher Scientific) using a SuperSignal West Femto Maximum Sensitivity substrate (Thermo Fisher Scientific).

\subsection{Lipidomic Analyses of Sertoli Cells and Sperm}

Using a modified Bligh and Dyer method [2,22], lipids were isolated from Sertoli cells detached from the culture plate by Accutase treatment. Major lipids from the same numbers of WT and $\mathrm{Arsa}^{-1-}$ Sertoli cells were then comparatively quantified by different modes of flow injection/ESI-MS/MS coupled with multiple reaction monitoring (MRM) as previously described $[1,19,23]$. Lipids extracted from 0.04 million and 0.008 million Sertoli cells were used per injection for initial global analyses and subsequent MRM quantifications, respectively. Lipids analyzed included sulfolipids (SGG and cholesterol sulfate (CS)), identified by precursor ion scanning in the negative mode (parents of $\mathrm{m} / \mathrm{z}$ 97 (sulfate group)); phosphatidylcholines (PCs) and sphingomyelins (SMs), identified by precursor ion scanning in the positive mode (parents of $\mathrm{m} / \mathrm{z} 184$ (choline group)); phosphatidylethanolamines (PEs), identified by neutral loss scanning in the positive mode (loss of $m / z 141$ (ethanolamine group)); cholesteryl esters (CEs), identified by precursor ion scanning in the positive mode (parents of $m / z 364.9$ (cholesteryl group)). The identities of candidate lipids were assigned by manually comparing the $m / z$ values obtained from the MS/MS analyses with those listed in the online lipid databases (retrieved on 15 December 2018 from http:/ / www.lipidmaps.org and http:/ / www.byrdwell.com/LipidAcademy). For SGG, its absolute amounts in Sertoli cells of WT and Arsa null mice were further obtained through flow injection/ESI-MS/MS-MRM by comparing the peak areas of parents of $\mathrm{m} / z 97$ in the samples with those of a standard curve built with known amounts (0.2-20 pmole/10- $\mu \mathrm{L}$ injection) of the deuterated form of SGG synthesized by us [24]. Since sulfatide (C16:0 SGC), upon subjection to ESI-MS/MS coupled with multiple reaction monitoring (MRM), produced the sulfate $m / z 97$ ion like SGG and deuterated SGG, SGC was quantified from the $m / z 97$ ion standard curve generated from the deuterated SGG standard. For lipids other than SGG and SGC, relative abundance between those present in WT and $\mathrm{Arsa}^{-1-}$ Sertoli cells was compared based on peak areas of each molecular species.

Lipids were also extracted from PGC sperm of 8-month-old WT and $\mathrm{Arsa}^{-1-}$ males and quantified for SGG and cholesterol sulfate (the two major sperm sulfolipids) by ESIMS/MS-MRM using deuterated SGG and cholesterol sulfate to build standard curves in a similar manner as described above.

Total cholesterol (free and CEs) in lipids extracted from Sertoli cells was quantified using Molecular Probes Amplex Red Cholesterol Assay Kit (Thermo Fisher Scientific, A12216) following the manufacturer's instruction. CEs present in the lipid sample were hydrolyzed by cholesterol esterase (provided in the kit) to cholesterol. In this assay, all free cholesterol was oxidized by cholesterol oxidase (provided in the kit) to yield $\mathrm{H}_{2} \mathrm{O}_{2}$ and cholestene-3-one. The produced $\mathrm{H}_{2} \mathrm{O}_{2}$ then reacted with the provided Amplex Red reagent, 10-acetyl-3,7-dihydroxyphenoxazine, as catalyzed by HRP (provided in the kit) to generate highly fluorescent resorufin. This assay was performed in a black-walled 96-well plate (Corning Inc., Corning, NY, USA). In each well of the plate, the lipid extract from 0.01 million Sertoli cells dissolved in $25 \mu \mathrm{L}$ of $100 \%$ ethanol was mixed with $25 \mu \mathrm{L}$ of $1 \mathrm{X}$ Reaction Buffer (100 mM potassium phosphate, $\mathrm{pH} 7.4,50 \mathrm{mM} \mathrm{NaCl}, 5 \mathrm{mM}$ cholic acid and $0.1 \%$ Triton X-100). This lipid solution was incubated $\left(30 \mathrm{~min}, 37^{\circ} \mathrm{C}\right)$ in the dark with $50 \mu \mathrm{L}$ of the Working Solution $(0.2 \mathrm{U} / \mathrm{mL}$ cholesterol esterase, $2 \mathrm{U} / \mathrm{mL} \mathrm{HRP}, 2 \mathrm{U} / \mathrm{mL}$ cholesterol oxidase, $300 \mu \mathrm{M}$ of Amplex Red reagent in 1X Reaction Buffer). In order to construct the cholesterol standard curve, cholesterol (0 to $1 \mu \mathrm{g}$ ) (in place of Sertoli cell lipids) was also subjected to the same incubations. The fluorescence of resorufin generated was measured in a fluorescence microplate reader, SpectraMAX GeminiXS (Molecular Devices, Sunnyvale, CA, USA), using the excitation and emission wavelengths of 560 and $590 \mathrm{~nm}$, respectively. Background fluorescence was measured from the well that contained the same volumes of 
all solutions but without any lipids and the value was used for subtraction from each data value. The assay was performed in duplicates of each Sertoli cell lipid sample.

2.7. Measurement of Superoxide Anion Levels in Sertoli Cells, Testicular Germ Cells, Seminiferous Tubules and Caput and Caudal Epididymis

2.7.1. Sertoli Cells

Sertoli cells cultured to $\sim 70-80 \%$ confluence on culture day 7 in a $6-\mathrm{cm}$ plate were washed twice with PBS containing $100 \mu \mathrm{M}$ of diethylenetriaminepentaacetic acid (DTPA, Sigma) (PBS/DTPA, $3 \mathrm{~mL}$ each wash). The Sertoli cell culture was then incubated (30 min, $35^{\circ} \mathrm{C}, 5 \% \mathrm{CO}_{2}$ ) with $3 \mathrm{~mL}$ of Gibco HBSS (Thermo Fisher Scientific, A14026-076) containing $100 \mu \mathrm{M}$ of DTPA (HBSS/DTPA) and $30 \mu \mathrm{M}$ of DHE (Sigma). At the end of the incubation, the Sertoli cell culture was washed twice with PBS/DTPA ( $3 \mathrm{~mL}$ each wash) and the cells were detached from the plate by treatment $\left(5 \mathrm{~min}, 35^{\circ} \mathrm{C}, 5 \% \mathrm{CO}_{2}\right)$ with $3 \mathrm{~mL}$ of Accutase. Sertoli cells were collected in a $15-\mathrm{mL}$ tube and washed twice in PBS-DTPA ( $3 \mathrm{~mL}$ each wash) by centrifugation $\left(800 \times g, 3 \mathrm{~min}, 28^{\circ} \mathrm{C}\right)$. The Sertoli cell pellet was added with $1 \mathrm{~mL}$ of acetonitrile and the mixture was sonicated in a cup using a Fisher Sonic Dismembranator Model 300 at $90 \%$ output for $3 \mathrm{~min}$. Following centrifugation at $12,000 \times \mathrm{g}$ for $10 \mathrm{~min}$ at $4{ }^{\circ} \mathrm{C}$ to pellet cell particulates, the cell extract in the supernatant was transferred to a fresh tube and dried under vacuum. The dried cell extract was kept at $-80^{\circ} \mathrm{C}$ in the dark until HPLC analyses.

\subsubsection{Testicular Germ cells}

TGCs ( 1 million) prepared as described above were incubated $\left(15 \mathrm{~min}, 35^{\circ} \mathrm{C}, 5 \%\right.$ $\mathrm{CO}_{2}$ ) in $500 \mu \mathrm{L}$ of HBSS/DTPA containing $1 \mu \mathrm{M}$ of PMA (phorbol myristate acetate (Sigma)), diluted from the $16 \mathrm{mM}$ stock solution, which was made in DMSO). The cells were then washed twice in $500 \mu \mathrm{L}$ of HBSS/DTPA $(800 \times g, 3 \mathrm{~min}, \mathrm{RT})$ and incubated $\left(10 \mathrm{~min}, 35{ }^{\circ} \mathrm{C}, 5 \% \mathrm{CO}_{2}\right)$ in $500 \mu \mathrm{L}$ of HBSS/DTPA containing $200 \mu \mathrm{M}$ of DHE. The unincorporated DHE was then washed off twice from TGCs with $500 \mu \mathrm{L}$ of PBS/DTPA by centrifugation $\left(1000 \times g, 5 \mathrm{~min}, 4{ }^{\circ} \mathrm{C}\right)$. Acetonitrile $(500 \mu \mathrm{L})$ was added to the TGC pellet and the mixture was sonicated at $90 \%$ output for $3 \mathrm{~min}$. The particulates were then removed by centrifugation and the cell extract was dried under vacuum and kept frozen in the same manner as described for Sertoli cells.

\subsubsection{Seminiferous Tubules}

The tubules isolated from two decapsulated testes as described above were washed twice in $5 \mathrm{~mL}$ of DMEM/F12 (containing no phenol red). They were allowed to sediment by unit gravity during the washes and were finally separated from the supernatant by passing the suspension through a $100 \mu \mathrm{m}$ cell strainer. The tubules were retained on the strainer and a small fraction of them were taken with the best attempt to remove residual medium from them. These tubules were about $1 \mathrm{mg}$ (ranging from 0.9 to $1.1 \mathrm{mg}$ ), as revealed by weighing. They were placed in a $1.5 \mathrm{~mL}$ Eppendorf tube containing $250 \mu \mathrm{L}$ of PBS/DTPA and cut into small $(1-2 \mathrm{~mm})$ pieces using small scissors. These tubule pieces were washed twice in the same buffer by centrifugation $\left(100 \times g, 3 \mathrm{~min}, 28^{\circ} \mathrm{C}\right)$, and then incubated ( $15 \mathrm{~min}$, $35^{\circ} \mathrm{C}$ ) in $500 \mu \mathrm{L}$ of PBS/DTPA containing $200 \mu \mathrm{M}$ of DHE. At the end of the incubation, the tubules were washed (100 g, $3 \mathrm{~min}$, RT) twice in $500 \mu \mathrm{L}$ of PBS/DTPA and the tubules sedimented as a pellet were snapped frozen in liquid nitrogen. The frozen tubule pellet was homogenized using a micro homogenizer and added with $500 \mu \mathrm{L}$ of acetonitrile. This was followed by sonification at $90 \%$ output for $3 \mathrm{~min}$. The sonicated tissue suspension was centrifuged at $12,000 \times \mathrm{g}$ for $10 \mathrm{~min}$ at $4{ }^{\circ} \mathrm{C}$ to pellet the particulates. The tissue extract in the supernatant was then vacuum dried and kept frozen until HPLC analyses.

\subsubsection{Caput and Cauda Epididymides}

A caput and cauda epididymis were dissected from a WT or Arsa null mouse and immediately cut into $1-5 \mathrm{~mm}$ pieces. Similar to the procedures used for seminiferous tubules, 
the epididymis pieces $(\sim 1 \mathrm{mg})$ were washed in PBS/DTPA, incubated in HBSS/DTPA containing DHE, and processed to obtain the cell extract, as described above.

\subsubsection{Quantification of Superoxide Anion}

Incorporated DHE was converted specifically by the superoxide anion through oneelectron oxidation to 2-hydroxyethidium (2HE). However, DHE was also oxidized through a two-electron reaction by hydrogen peroxide and other oxidants inside the cells to become ethidium (Eth), which has a similar excitation and emission spectra as 2HE. Therefore, 2HE and Eth, as well as unreacted DHE, were first separated from each other by HPLC [25,26]. The dried samples were each dissolved in $120 \mu \mathrm{L}$ of $20 \%$ methanol and $0.1 \%$ trifluoroacetic acid and $100 \mu \mathrm{L}$ of the suspension was injected into an Agilent 1100 HPLC system with an Agilent Zorbax 300SG C18 column (5 $\mu$ m internal diameter). A gradient consisting of solution A (20\% methanol and $0.1 \%$ trifluoroacetic acid) and solution B (100\% methanol) was applied to the column to separate DHE, Eth and 2HE from each other. The gradient started at $0 \%$ solution B and was increased linearly to $50 \%$ solution A within the first $10 \mathrm{~min}$. Solutions were then held for $10 \mathrm{~min}$ followed by a wash with $100 \%$ solution B for $5 \mathrm{~min}$. The system was subsequently equilibrated with 100\% solution A for a further $10 \mathrm{~min}$. The DHE peak was detected by its UV absorption at $245 \mathrm{~nm}$, whereas detection of the Eth and 2HE was carried out by their fluorescence signals with the excitation and emission wavelengths set up at 480 and $580 \mathrm{~nm}$, respectively. All separated products were quantified by comparing the peaks to those of the known standards and the results were expressed as the ratio of $2 \mathrm{HE}$ (nmole) to DHE ( $\mu$ mole) and Eth (nmole) to DHE ( $\mu$ mole). The former ratio 2HE/DHE specifically reflected the amount of superoxide anion inside the cells/tissues. Both the 2HE/DHE and E/DHE in cells and tissues of $\mathrm{Arsa}^{-/-}$mice were expressed as relative to the corresponding values in age-matched WT mice, which were designated as 1 .

\subsection{Measurement of Hydrogen Peroxide in Sertoli Cells and Epididymal Fluid}

$\mathrm{H}_{2} \mathrm{O}_{2}$ produced by Sertoli cells or present in epididymal fluid was quantified using Molecular Probes Amplex Red Hydrogen Peroxide Assay Kit (Thermo Fisher Scientific, A22188) with a modification. In this assay, HRP (provided in the kit) catalyzes the oxidation by $\mathrm{H}_{2} \mathrm{O}_{2}$ and other oxidants in the cells of the Amplex Red reagent into fluorescent resorufin.

Sertoli cells cultured in two $10-\mathrm{cm}$ plates to $~ 70-80 \%$ confluence on culture day 7 were first washed twice with sterile PBS (prewarmed to $\left.35^{\circ} \mathrm{C}\right)(5 \mathrm{~mL} /$ plate/wash). Each Sertoli cell plate was then incubated with $3 \mathrm{~mL}$ of $1 \mathrm{X}$ Reaction Buffer $(0.05 \mathrm{M}$ sodium phosphate, $\mathrm{pH}$ 7.4) at $35^{\circ} \mathrm{C}$ for $1 \mathrm{~h}$. At the end of the incubation, the cells were scraped off both plates and combined for centrifugation $(500 \times g, 3 \mathrm{~min})$. The supernatant was then discarded and the cell pellet was resuspended in 1X Reaction Buffer, so that the final volume of the cell suspension was $220 \mu \mathrm{L}$. For each assay point, $50 \mu \mathrm{L}$ of the Sertoli cell suspension was used and the assay of each sample was performed in triplicates in a black-walled 96-well plate. Another $50 \mu \mathrm{L}$ of the same Sertoli cell suspension was also placed in a well of the 96-well plate for treatment $\left(1 \mathrm{~h}, 37^{\circ} \mathrm{C}\right.$ ) with $10 \mu \mathrm{L}$ of polyethylene glycol (PEG)-catalase (500 IU, Sigma, cat. no. C4963; stock solution made in 1X Reaction Buffer), which would induce the breakdown of $\mathrm{H}_{2} \mathrm{O}_{2}$ into $\mathrm{H}_{2} \mathrm{O}$ and $\mathrm{O}_{2}$. The triplicate wells of untreated Sertoli cell suspension were added with $10 \mu \mathrm{L}$ of Reaction Buffer and incubated in parallel. Finally, all wells were added with $50 \mu \mathrm{L}$ of the Working Solution containing $100 \mu \mathrm{M}$ Amplex Red reagent and $0.2 \mathrm{U} / \mathrm{mL}$ HRP in the Reaction Buffer and incubated (30 min, RT) in the dark. Fluorescent resorufin generated was then measured using a FLUOstar Galaxy Microplate Reader (BMG Labtechnologies, Ortenberg, Germany) with the excitation and emission setups as described in the cholesterol assay. The fluorescence specific to $\mathrm{H}_{2} \mathrm{O}_{2}$ induction was obtained by subtracting the untreated sample value with the catalase-treated value.

An aliquot $(10 \mu \mathrm{L})$ of the remaining Sertoli cell suspension was subjected to cell counting using a hemocytometer. The fluorescent values or resorufin obtained were then expressed as arbitrary fluorescence units per 0.2 millions of Sertoli cells. 
$\mathrm{H}_{2} \mathrm{O}_{2}$ in the epididymal fluid was also quantified. Using a pair of forceps, epididymal fluid containing sperm was squeezed out from the cauda epididymis pre-scored longitudinally with a razor blade. The milk-like fluid was immersed immediately into $200 \mu \mathrm{L}$ of KRB-HEPES, which was subjected to centrifugation $\left(1000 \times \mathrm{g}, 10 \mathrm{~min}, 28^{\circ} \mathrm{C}\right)$ to pellet sperm. The supernatant was re-centrifuged at $14,000 \times g\left(5 \mathrm{~min}, 28^{\circ} \mathrm{C}\right)$ to pellet any cellular debris and particulates. The final supernatant representing diluted epididymal fluid $(50 \mu \mathrm{L})$ was used for $\mathrm{H}_{2} \mathrm{O}_{2}$ quantification, following the same protocol as described above. The resorufin fluorescent values were expressed as arbitrary fluorescence units per $10 \mu \mathrm{L}$ of epididymal fluid.

\subsection{Measurement of Antioxidants in Epididymal Fluid}

Total antioxidant levels in epididymal fluid of 8-month-old $\mathrm{Arsa}^{-/-}$and WT mice were determined using the Antioxidant Assay Kit (Cayman Chemical, MI, USA, Cat. No. 709001). This assay was based on the ability of antioxidants in the sample to inhibit the oxidation of ABTS (2,2'-azino-di-[3-ethylbenzthiazoline sulphonate]) to ABTS $\bullet+$ (with absorbance at $750 \mathrm{~nm}$ ) by metmyoglobin. In parallel, the assay was set up with a positive control antioxidant, Trolox (a water-soluble tocopherol analogue), in place of the sample. The levels of antioxidants in the sample were quantified as millimolar Trolox equivalents.

To prepare the sample from each mouse, the epididymal fluid containing sperm was collected from the cauda epididymis into $1 \mathrm{~mL}$ of PBS. This was followed by the removal of sperm and cellular debris and particulates by centrifugation as described above. The supernatant was then diluted 1:10 with the Assay buffer $(5 \mathrm{mM}$ potassium phosphate, $\mathrm{pH}$ 7.4, containing $0.9 \%$ sodium chloride and $0.1 \%$ glucose) prior to assaying following the manufacturer's instruction. The antioxidant concentrations were reported as millimolar Trolox equivalents in the original epididymal fluid collected in $1 \mathrm{~mL}$ of PBS.

\subsection{Detection of Apoptosis in Sertoli Cells}

The late stage of apoptosis in Sertoli cells was detected by the presence of nicks in DNA, using a Roche In Situ Cell Death Detection Kit, TMR Red (Millipore Sigma), following the manufacturer's instructions. Sertoli cells were prepared as described above with the exception that DNase I was omitted in all enzyme solutions. DMEM/F12 with proper supplements were used in the cell preparation and culture prior to the apoptosis assay. Approximately, 1-2 × $10^{6}$ Sertoli cells, Accutase detached from the substratum, were washed $(800 \times g, 3 \mathrm{~min}, \mathrm{RT})$ once in $100 \mu \mathrm{L}$ of PBS and then fixed $(1 \mathrm{~h}, \mathrm{RT})$ in $100 \mu \mathrm{L}$ of $4 \%$ PFA. The cells were then washed $(800 \times g, 3 \mathrm{~min}, \mathrm{RT})$ in PBS twice and the cell suspension was divided equally into three aliquots. One aliquot serving as a negative control was incubated $\left(60 \mathrm{~min}, 37^{\circ} \mathrm{C}\right)$ in the dark with $50 \mu \mathrm{L}$ of Label Solution (containing only tetramethylrhodamine (TMR)-dUTP, provided in the kit). The second aliquot to be assessed for the presence of nicks in DNA in vivo was incubated $\left(60 \mathrm{~min}, 37^{\circ} \mathrm{C}\right)$ in the dark with $50 \mu \mathrm{L}$ of TUNEL Reaction Mixture (prepared by mixing Label Solution and Enzyme Solution (containing deoxynucleotidyl transferase (TdT) enzyme) as per instruction in the kit). The third aliquot serving as a positive control was treated (15 min, RT) with DNase I $(200 \mu \mathrm{g} / \mathrm{mL})$ in $50 \mathrm{mM}$ Tris- $\mathrm{HCl}$ containing $0.1 \%$ BSA to generate as many nicks as possible in DNA. After the treatment, cells in the third aliquot were incubated with TUNEL Reaction Mixture in the same manner as cells in the second aliquot. Cells of the three aliquots were then washed ( $800 \mathrm{~g}, 3 \mathrm{~min}$, RT in $100 \mu \mathrm{L}$ of PBS) twice, resuspended in $30 \mu \mathrm{L}$ of PBS and applied onto a slide topped with a cover slip for viewing under a Zeiss Axio epifluorescence microscope using the rhodamine filter.

\subsection{Statistical Analyses}

All quantitative results were expressed as means \pm SDs from 3 or more replicate samples. Student's $t$-test was used to determine significant differences of the data between $\mathrm{Arsa}^{-/-}$and WT samples. 


\section{Results}

\subsection{Localization of ARSA, Saposin B and SGG in the Lysosomes of WT Sertoli Cells}

Immunofluorescence studies revealed that ARSA, saposin B, and the majority of SGG were co-localized with LAMP1 (a lysosome marker), in primary cultures of Sertoli cells from 8-month-old WT mice (Figures 1 and 2), indicating that these macromolecules were present in the lysosome. This was expected, since the enzyme ARSA and its co-enzyme, saposin B, have been known as lysosomal components with SGG as their substrate [1,27]. However, anti-saposin B-reacting signals were also observed in the cytoplasm and may have reflected the precursor form of saposin B, i.e., prosaposin, which is known for its presence in the Sertoli cell cytoplasm [28]. On the other hand, a small population of SGG in the cytoplasm with a granular pattern was noted (Figure 2), suggesting its presence in membranated organelles such as endosomes. It was possible that this SGG population was the newly phagocytosed lipid, which had not yet been transported to lysosomes.
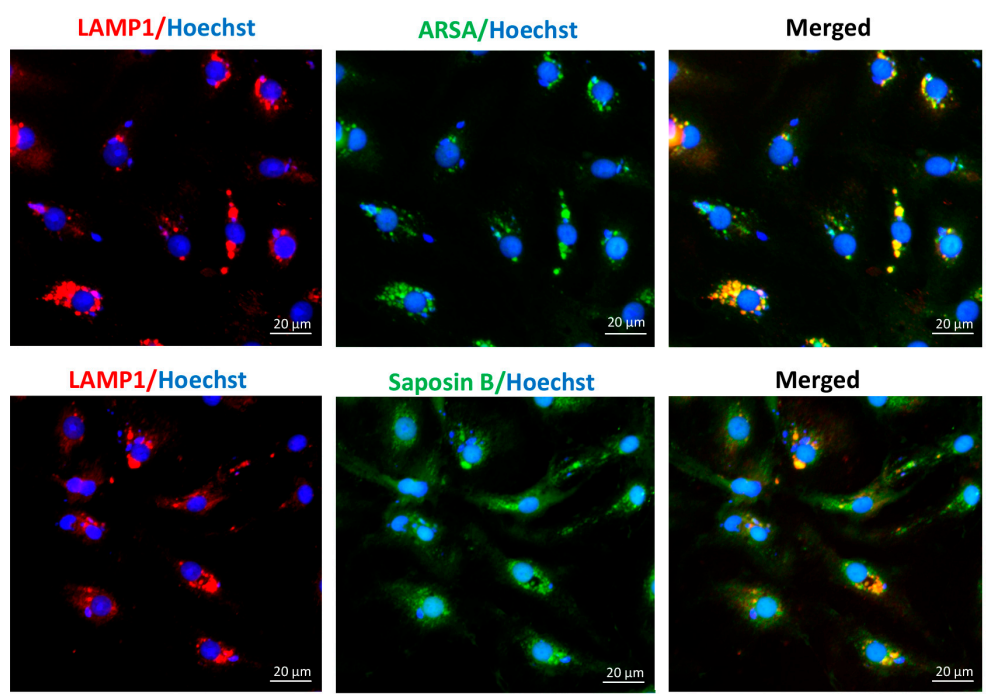

Figure 1. Immunolocalization of ARSA and LAMP1 (top panel), and saposin B and LAMP1 (bottom panel) in Sertoli cells from 8-month-old WT mice. Left and middle panels show LAMP1 and ARSA or saposin B localization, respectively, whereas the right panels display the merged signals of ARSA with LAMP1 and saposin B with LAMP1. Results shown are representative from three replicate experiments.
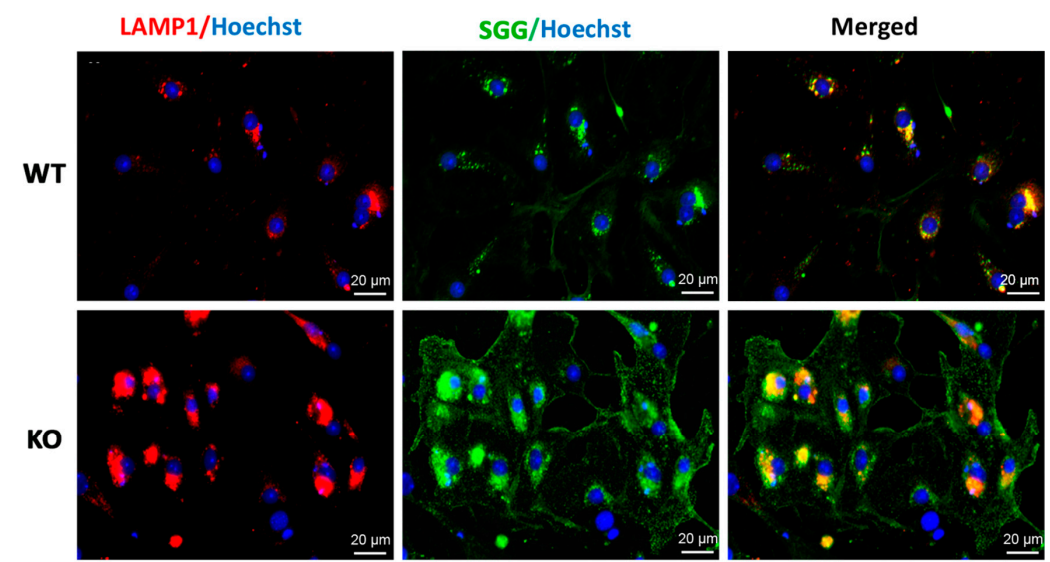

Figure 2. Immunolocalization of SGG and LAMP1 in Sertoli cells from 8-month-old WT mice (top panel) and in Sertoli cells from age-matched $\mathrm{Arsa}^{-/-}$mice (bottom panel). Left and middle panels show LAMP1 and SGG localization, respectively, whereas the right panels display the merged signals of SGG with LAMP1. Results shown are representative from three replicate experiments. 
3.2. Increased Amounts of SGG and Its Additional Localization in the Cytoplasm in Sertoli Cells of 8-Month-Old Arsa Null Mice

\subsubsection{Immunofluorescence Studies}

Increases in SGG amounts in Sertoli cells from 8-month-old Arsa null mice, as compared with Sertoli cells from age-matched WTs, were observed. These increases were evident by higher immunofluorescence intensity of SGG in the lysosome as well as strong immunofluorescent signals present as the granular pattern in the cytoplasm as well as on the cell surface of $\mathrm{Arsa}^{-/-}$Sertoli cells (Figure 2, bottom panels vs. top panels). The results indicated that SGG was accumulated in $\mathrm{Arsa}^{-/-}$Sertoli cells due to the failure to be catabolically processed because of the lack of ARSA (see Supplemental Figure S1), the first enzyme in the SGG degradation pathway [1]. However, saposin B was still present in the lysosome and cytoplasm of $\mathrm{Arsa}^{-/-}$Sertoli cells, similar to the observation in the WT counterparts (Supplemental Figure S2). It was also noted that the LAMP1 signal in $\mathrm{Arsa}^{-/}$Sertoli cells was much stronger than that in WT Sertoli cells (Figure 2), implicating the distention of the organelle.

\subsubsection{Lipidomic Analyses of SGG and Other Lipids}

ESI-MS/MS revealed that SGG was the prevalent sulfolipid present in Sertoli cells of both 8-month-old WT and Arsa null mice, with the SGG (C16:0/C16:0, $m / z$ 795.5) being the major molecular species (Figure 3A). However, low amounts of other SGG molecular species, including the SGG (C16:0/C14:0, $m / z$ 768.0/767.5), (C18:1/C16:0, $m / z$ 822.0/821.5) and (C18:0/C16:0, $m / z$ 823.5) species were also present in WT and $\mathrm{Arsa}^{-1-}$ Sertoli cells. On the other hand, an additional SGG molecular species (C20:4/C16:0, $m / z$ 843.5) and an analogue of SGG, sulfatide SGC (C16:0, $m / z$ 778.5) were selectively present in $\mathrm{Arsa}^{-1-}$ Sertoli cells (Figure 3B,C). Quantitative analyses by MRM indicated that the amount of SGG (C16:0/C16:0) in $\mathrm{Arsa}^{-/-}$Sertoli cells was twice that of the WT counterpart (4.40 \pm 1.76 versus $1.79 \pm 0.73$ nmole $/ 10^{6}$ cells with $p<0.05$ ). The levels of the SGG molecular species $(m / z$ 843.5, 821.5 and 823.5$)$ and SGC $\left(m / z\right.$ 778.5) were also significantly higher in $\mathrm{Arsa}^{-/-}$ Sertoli cells (Figure 3C).

The levels of total cholesterol (free + cholesteryl esters), as analyzed by Amplex Red assay with the inclusion of cholesterol esterase in the reaction mixture, were significantly decreased in $\mathrm{Arsa}^{-1}$ Sertoli cells, as compared with those in WT Sertoli cells (i.e., $164.21 \pm 20.20$ versus $204.01 \pm 45.45$ nmole $/ 10^{6}$ cells, $p<0.05$ ) (Figure 4 ).

ESI-MS/MS revealed that there was a trend towards decreased levels of various molecular species of PCs and SMs in Arsa ${ }^{-/}$Sertoli cells relative to those in WT counterparts. However, except for lysoPC (C16:0), these decreases were not statistically different (Supplemental Figure S3). The levels of PEs and CEs also appeared to be similar in $\mathrm{Arsa}^{-1-}$ and WT Sertoli cells (Supplemental Figures S4 and S5).

3.3. Increased ROS Levels in Sertoli Cells, Testicular Germ Cells, and Seminiferous Tubules of Arsa Null Mice

Following incubation with DHE, the levels of 2HE, representing superoxide anion, in Sertoli cells from $\mathrm{Arsa}^{-/-}$mice were increased as compared with the corresponding levels in Sertoli cells from age-matched WT mice. However, the increase was only significant statistically in Sertoli cells isolated from 5-month-old mice (Figure 5A). A similar result was observed with the levels of Eth (representing other ROS and other oxidants inside the cells) (Figure 5A). Testicular germ cells incubated with DHE also showed increases in both $2 \mathrm{HE}$ and Eth in $\mathrm{Arsa}^{-/-}$mice of both ages, and all increased levels in the Arsa ${ }^{-1-}$ samples, as compared with the WT samples, were significant (Figure 5B). Since seminiferous tubules comprise TGCs and Sertoli cells, they were subjected to the same analyses. Increased levels of $2 \mathrm{HE}$ and Eth were likewise observed in $\mathrm{Arsa}^{-/-}$samples, with statistical significance for both 2HE and Eth in seminiferous tubules from 5-month-old $\mathrm{Arsa}^{-/-}$and WT animals. For seminiferous tubules isolated from animals 8 months of age, only the increase in $2 \mathrm{HE}$ (superoxide) levels in $\mathrm{Arsa}^{-1-}$ seminiferous tubules was significant (Figure 5C). 
A

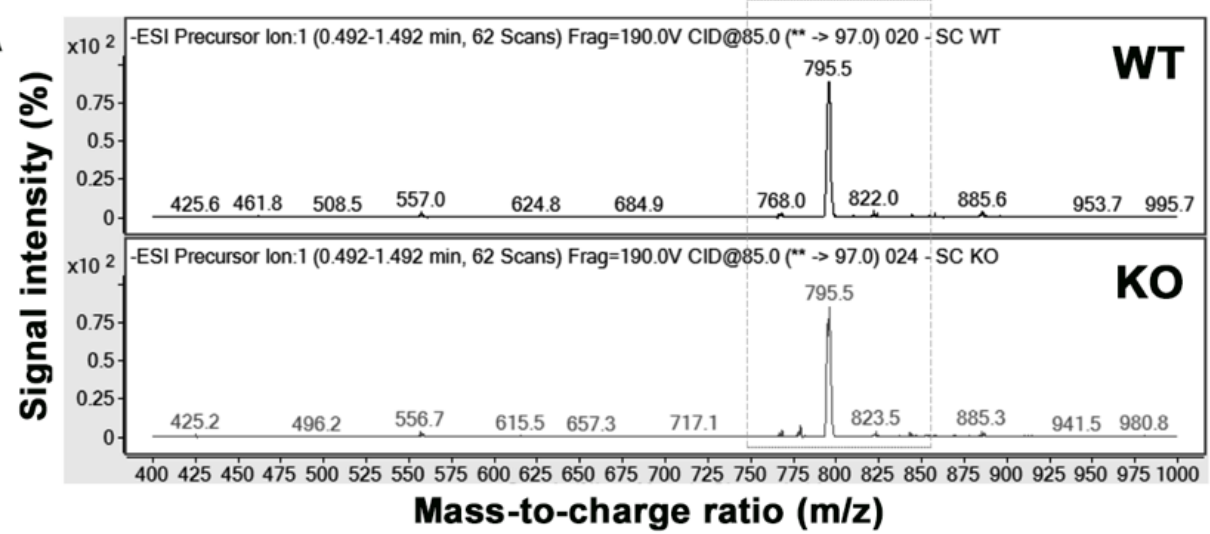

B

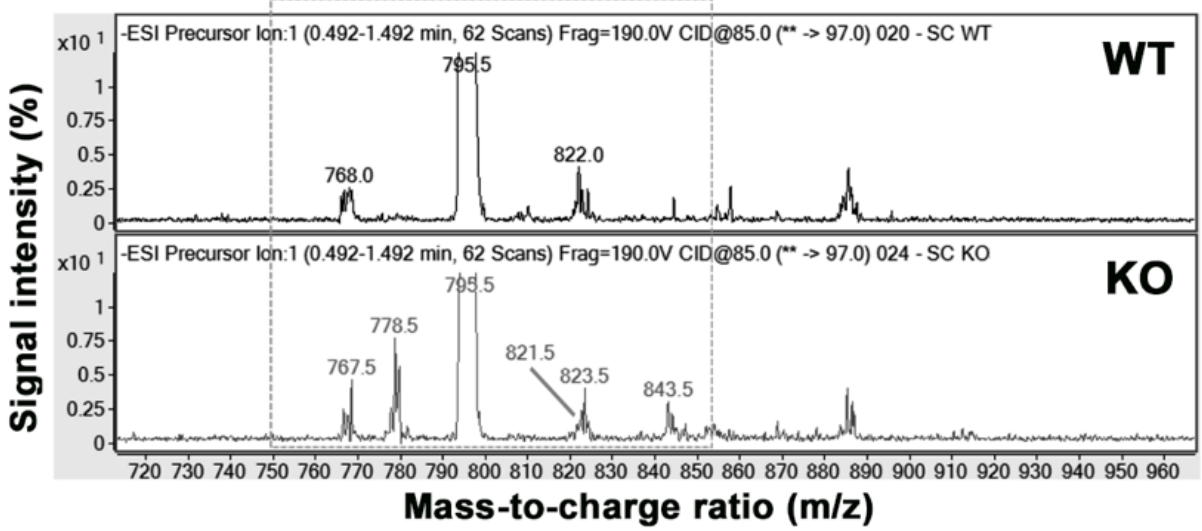

C

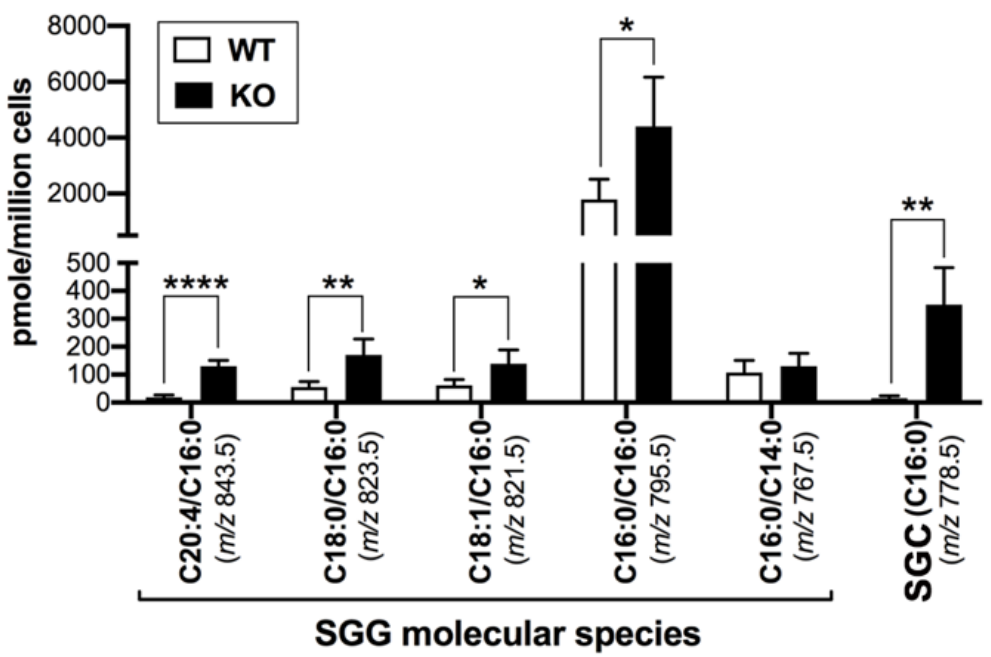

Figure 3. ESI/MS-MS spectra from precursor ion scanning of $m / z 97$ (sulfate group) showing major sulfolipids in Sertoli cells from 8-month-old wild type (WT) and Arsa KO mice. (A) Representative mass spectra of one out of four sets of WT and KO samples were shown. Note that SGG (C16:0/C16:0) with $m / z 795.5$ was the most abundant sulfolipid in both WT and KO Sertoli cells. (B) Magnified view of the mass spectra in the range of $m / z 720-960$ showing the presence of three SGG molecular species (C16:0/C14:0 with $m / z$ 768.0/767.5; C18:1/C16:0 with $m / z$ 821.5/822.0; C18:0/C16:0 with $m / z$ 823.5) in both WT and KO Sertoli cells, as well as the selective presence of another SGG molecular species, (C20:4/C16:0, $m / z$ 843.5), and a sulfatide SGC (C16:0) with $m / z 778.5$ in the KO sample. (C) Comparative amounts of various SGG molecular species and sulfatide (SGC (C16:0)), as determined by tandem MS coupled with MRM, in WT and Arsa KO Sertoli cells. Results shown are from four replicate experiments. ${ }^{*}, * * * * * *$ denote $p<0.05,0.01$ and 0.0001 , respectively. 


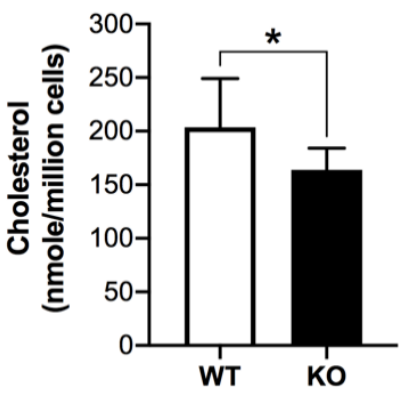

Figure 4. Decreased amounts of total cholesterol in Sertoli cells from 8-month-old Arsa KO mice as compared with Sertoli cells from age-matched WT mice. * denotes a significant difference $(p<0.05)$ of the cholesterol amounts between the two samples. Results shown are from six replicate experiments.

A

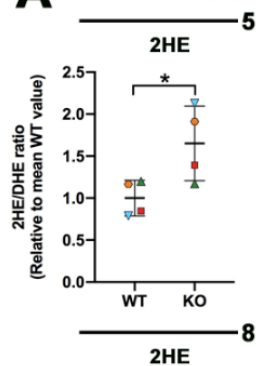

Sertoli cells

months
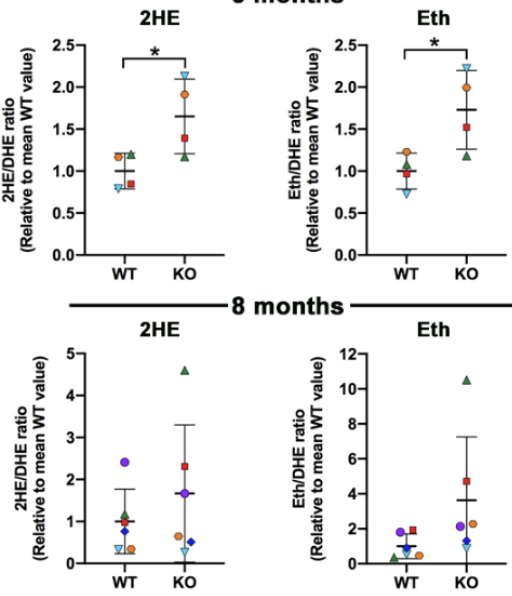

C Seminiferous tubules
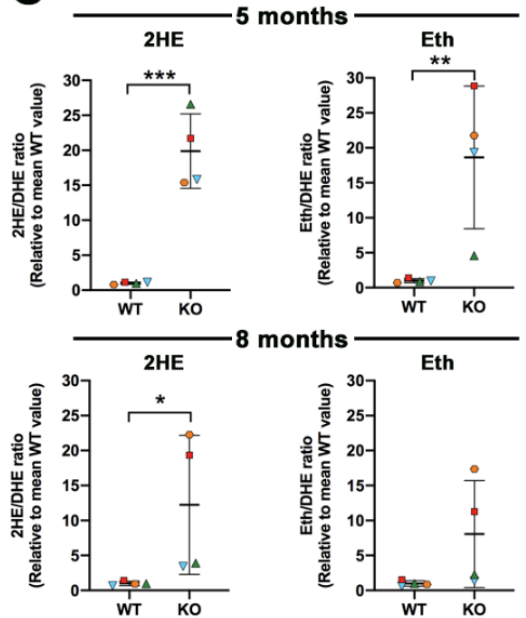

B
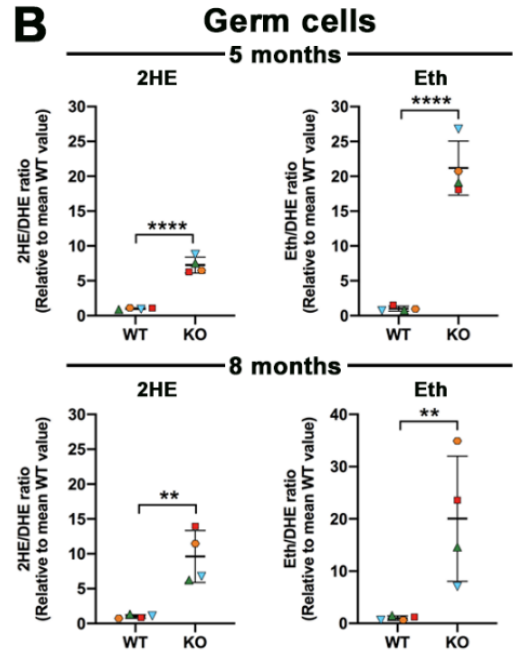

Figure 5. ROS levels in Sertoli cells (A), testicular germ cells (B) and seminiferous tubules (C) from Arsa $\mathrm{KO}$ mice and age-matched WT mice, 5 months and 8 months of age. Cells and minced tissues were incubated with DHE. Superoxide generated intracellularly converted DHE to $2 \mathrm{HE}$, whereas other ROS and oxidants changed DHE to Eth. Changes of 2HE/DHE and Eth/DHE in cells and tissues from Arsa $\mathrm{KO}$ mice were expressed as fold increases from corresponding values from agematched WT mice. Results on Sertoli cells from 8-month-old WT and Arsa KO mice were from 6 replicate experiments, whereas those on Sertoli cells from 5-month-old WT and Arsa KO mice, and testicular germ cells and seminiferous tubules from WT and KO mice of both ages were each from 4 replicate experiments. ${ }^{*}, * *, * * * * * * *$ denote $p<0.05,0.01,001$ and 0.0001 , respectively. 
Since Sertoli cells are known to possess superoxide dismutase (SOD) [29,30], superoxide anion produced in these cells would continuously be converted to $\mathrm{H}_{2} \mathrm{O}_{2}$, which could be directly quantified by the Amplex Red assay. Figure 6 shows that the levels of $\mathrm{H}_{2} \mathrm{O}_{2}$ in Sertoli cells from both 5-month-old and 8-month-old $\mathrm{Arsa}^{-/-}$mice were significantly higher than those in Sertoli cells from age-matched WT animals.

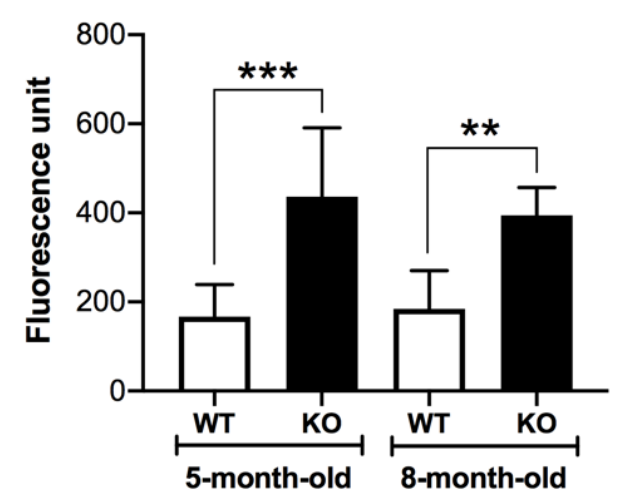

Figure 6. Higher $\mathrm{H}_{2} \mathrm{O}_{2}$ levels in Sertoli cells from 5-month-old and 8-month-old Arsa KO mice, as compared with Sertoli cells from age-matched WT counterparts. Results were from 3 replicate experiments. ${ }^{* *}, * * *$ denote $p<0.01$ and 0.001 , respectively.

3.4. Increased Apoptosis in the Primary Cultures of Sertoli cells from 8-Month-Old Arsa ${ }^{-/}$Mice

Spermatogenesis occurs at a 50\% wild type rate in 8-month-old $\mathrm{Arsa}^{-1-}$ mice [17]. Considering that Sertoli cells have important roles in supporting TGC development during spermatogenesis [1], we investigated whether Sertoli cells were impaired and/or lower in number in 8-month-old $\mathrm{Arsa}^{-/-}$mice, as compared with those in age-matched WT mice. Herein, we showed that the primary cultures of Sertoli cells from $\mathrm{Arsa}^{-/}$mice at this age had much higher rates of apoptosis as compared with Sertoli cells from counterpart WT mice. On culture day 4, the apoptosis rate was only $18.8 \pm 3.4 \%$ in the WT Sertoli cell culture but it was $61.7 \pm 16.1 \%$ in the Arsa $^{-/}$Sertoli cell culture $(p<0.0001)$. On culture day 7, the difference in the apoptotic rates between WT and $\mathrm{Arsa}^{-/-}$cultures was also significant, i.e., $36.9 \pm 6.1 \%$ for WT Sertoli cells and $82.0 \pm 3.1 \%$ for $\mathrm{Arsa}^{-/-}$Sertoli cells $(p<0.0001)$ (Figure 7). When Sertoli cells were isolated from 8-month-old $\mathrm{Arsa}^{-1-}$ mice or counterpart WT animals and plated for attachment to the culture dish surface, the numbers of adherent Sertoli cells per mouse from $\mathrm{Arsa}^{-1-}$ mice were only half of the values from WT animals (Figure 8). This increased rate of apoptosis in Arsa $^{-/}$Sertoli cells may have occurred in vivo. As expected, the numbers of TGCs isolated from each 8-month-old $\mathrm{Arsa}^{-/}$mouse were also $50 \%$ of the numbers from each age-matched WT mouse (Supplemental Figure S6).

\subsection{Increased ROS Levels in the Epididymis of Aging Arsa Null Mice}

Significant increases in 2HE (superoxide) and Eth (other ROS and oxidant) levels were observed in the cauda epididymis from 8-month-old $\mathrm{Arsa}^{-/-}$mice, as compared with age-matched WT mice (Figure 9A). Similar results were also noted in the cauda epididymis of 5-month-old animals, as well as in the caput epididymis of both 5-month-old and 8-month-old mice (Supplemental Figure S7). The levels of $\mathrm{H}_{2} \mathrm{O}_{2}$ in the caudal epididymal fluid were also higher in $\mathrm{Arsa}^{-/-}$mice relative to the WT counterparts (Figure 9B). The lower levels of antioxidants, as measured from the caudal epididymal fluid, in $\mathrm{Arsa}^{-/-}$ mice (Figure 9C), could partially contribute to the higher levels of ROS in this tissue of the $\mathrm{KO}$ mice. 


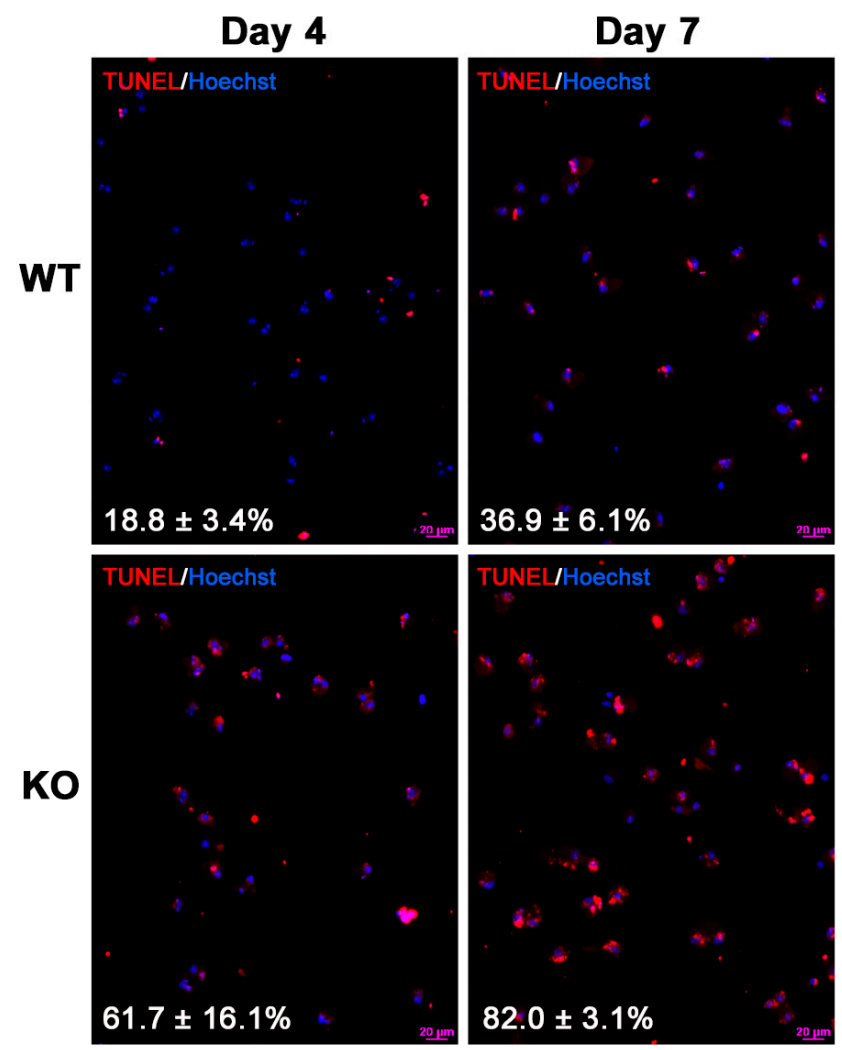

Figure 7. Sertoli cells from 8-month-old Arsa KO mice underwent higher rates of apoptosis in culture than Sertoli cells from age-matched WT males. Sertoli cells from Arsa KO and WT mice were cultured in parallel and the TUNEL assay was performed on culture day 4 and day 7. Fluorescent images of Sertoli cells from WT and KO mice showing incorporation of TMR-dUTP (red fluorescence) into the nucleus (Hoechst blue fluorescence) were displayed along with percentages of apoptotic cells (TMR-dUTP positive) in the bottom left. Results were from 3 replicate experiments.

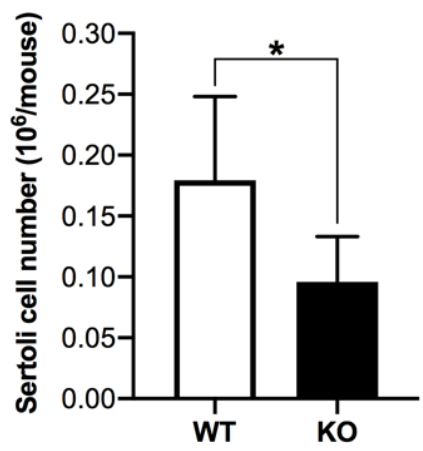

Figure 8. Lower yields of cultured Sertoli cells from 8-month-old Arsa KO mice, compared with those from age-matched WT mice. Sertoli cells were detached by Accutase treatment from the culture plate on culture day 7 and counted under a microscope. Results were from 4 replicate Sertoli cell isolations from the WT and KO animals. Four WT mice and 7-8 KO mice were used in each Sertoli cell isolation. * denotes $p<0.05$.

3.6. Aberrant Levels of Sulfolipids and Abnormal Morphology of Sperm from Aging Arsa-l- Mice

Our previous studies indicate that caudal epididymal sperm from 8-month-old Arsa-/mice have minimal fertilizing ability, and our SGG quantification in pooled sperm samples also reveal a 50\% level in the $\mathrm{KO}$ mice, as compared with age-matched WT animals [17]. In this report, our sulfate precursor ion scanning indicated that SGG and cholesterol sulfate were the two main sperm sulfolipids (Supplemental Figure S8). Quantification of these two 
sulfolipids from PGC sperm collected separately from $\mathrm{Arsa}^{-/-}$mice and WT mice, both 8 months of age, revealed that sperm SGG levels in the KO mice were decreased $\sim 50 \%$, as compared with the corresponding WT levels (Figure 10), a result corroborating our previous observation [17]. In contrast, the levels of sperm cholesterol sulfate in $\mathrm{Arsa}^{-1-}$ mice increased to about twice the amounts in WT mice (Figure 10).
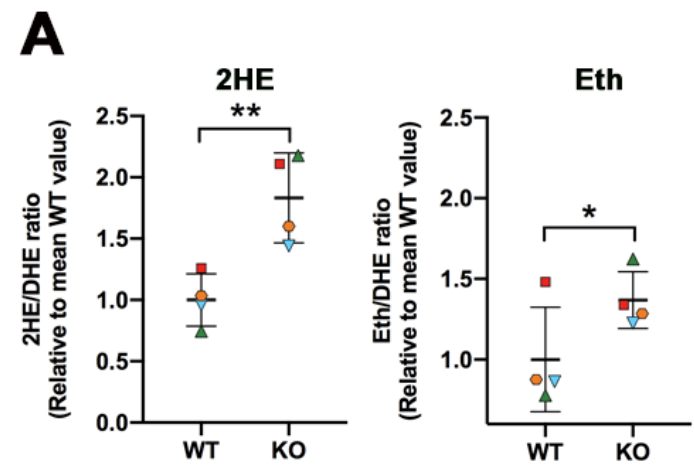

B
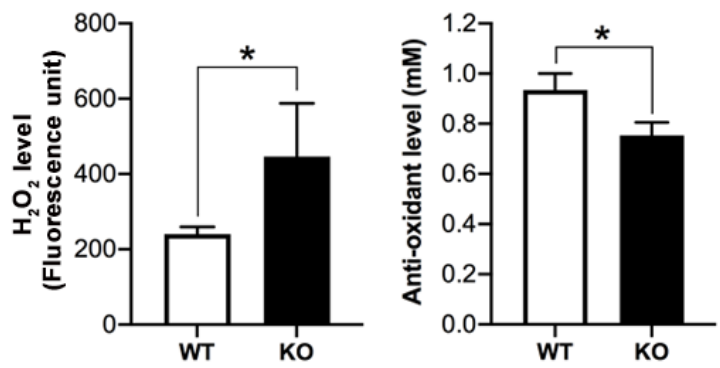

Figure 9. (A). Higher superoxide anion levels (2HE) and other ROS plus oxidants (Eth) in the cauda epididymis of 8-month-old Arsa null mice, compared with age-matched WT mice. Data from the $\mathrm{KO}$ mice were expressed as fold increases over the corresponding values from WT mice in a similar manner as described in the Figure 5 legend. Results were from four replicate experiments. Higher amounts of $\mathrm{H}_{2} \mathrm{O}_{2}$ (B) but lower levels of antioxidants (C) in the caudal epididymal fluid of 8-monthold Arsa KO mice, compared with the counterpart fluid of age-matched WT mice were also displayed. Results on both quantifications were from three replicate experiments. ${ }^{*}{ }^{* *}$ denotes $p<0.05$ and 0.001 , respectively.

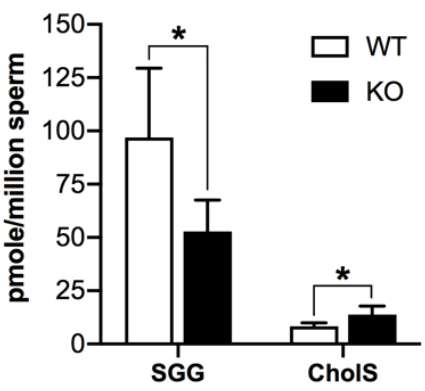

Figure 10. Changes of sulfolipid levels in sperm from 8-month-old Arsa KO mice, as compared with sperm from age-matched WT mice. Two main sperm sulfolipids, SGG and cholesterol sulfate (CholS) were quantified by ESI-MS/MS-MRM. Results were from three replicate analyses. In each analysis, 3 and $10 \mathrm{WT}$ and Arsa KO mice were used to prepare Percoll-gradient-centrifuged sperm, respectively, from which lipids were extracted for lipidomics work. * denotes $p<0.05$.

Changes of sperm morphology from the WT characteristics appeared to correlate with aberrant levels of sperm sulfolipids in $\mathrm{Arsa}^{-/-}$mice. In normal fertile animals, the subjection of caudal epididymal sperm to Percoll density gradient centrifugation results 
in the separation of sperm into two populations, i.e., pelleted sperm in the bottom of the tube and sperm interfaced between the two Percoll gradient solutions $(35 / 70 \%$ gradient or $45 / 90 \%$ gradient). The pelleted sperm population, constituting about $65 \%$ of total sperm, has a high fertilizing ability due to normal sperm morphology, and great motility upon resuspension in medium. On the other hand, the interfaced sperm population (the remaining $35 \%$ ) is mainly immotile with minimal fertilizing ability. Electron microscopic analyses also reveal the abnormal ultrastructure of interfaced sperm, for example, membranated vesicles surrounding the sperm head and midpiece, and incomplete chromatin condensation [20]. The distribution of the pelleted and interfaced sperm populations of 8-month-old WT mice was as expected for normal fertile animals, i.e., $65 \%$ and 35\%, respectively (Figure 11A). Although the morphology of almost all of the WT interfaced and pelleted sperm was not distinguishable from each other by light microscopy (Figure 11B), the motility of the two sperm populations was drastically different. More than $90 \%$ of WT pelleted sperm were motile, whereas the majority of WT interfaced sperm were immotile (data not shown).
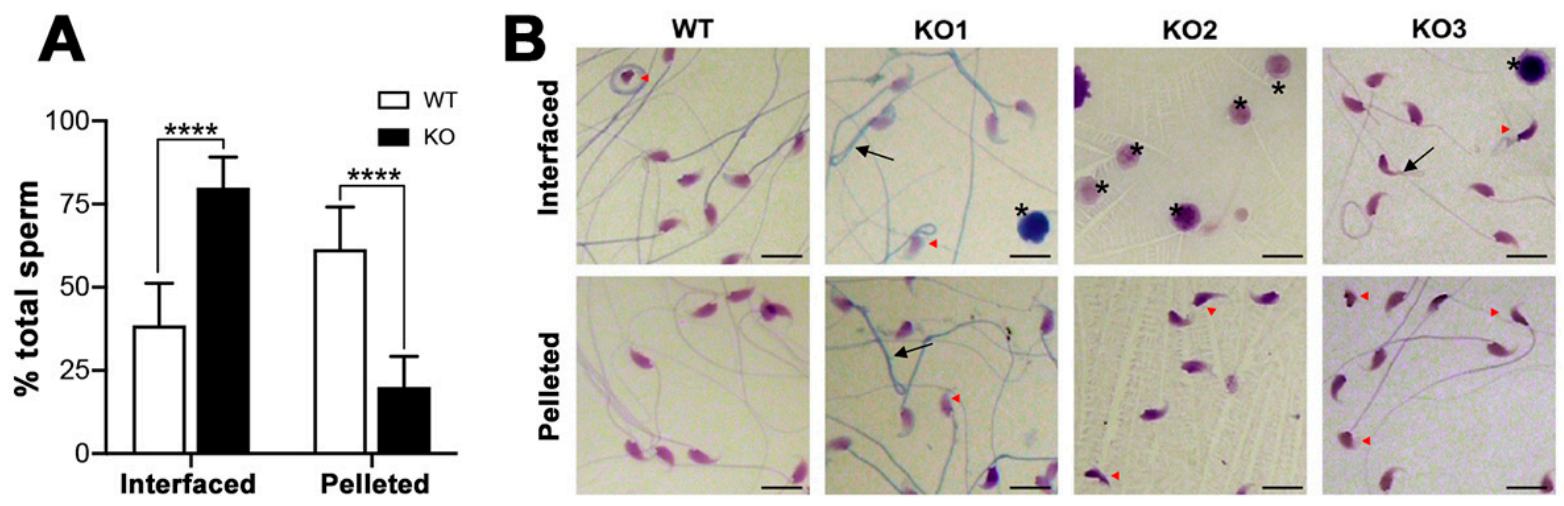

Figure 11. An increase in sperm with abnormal morphology in Arsa KO mice, 8 months of age, as compared with agematched WT sperm. Caudal epididymal sperm from Arsa KO and WT mice were separately subjected to Percoll gradient (35/70\%) centrifugation. (A) Distribution of WT and Arsa KO sperm interfaced between the two Percoll solutions and those pelleted after Percoll gradient centrifugation. Results were expressed as means \pm SDs of total sperm from 7 each of WT or Arsa KO sperm preparations, performed in parallel. Sperm (and immature germ cells) retrieved from 2-4 WT or 4-8 Arsa KO mice were used in each Percoll gradient centrifugation. ${ }^{* * * *}$ denotes $p<0.0001$. (B) Select morphological images of sperm sedimented as the pellet or at the Percoll gradient interface. Images from only $1 \mathrm{WT}$ sample were shown as the results were very consistent throughout all WT samples. Images of pelleted and interfaced sperm in three preparations (KO1, KO2 and KO3) from Arsa KO mice were shown in comparison. Red arrow heads and black arrows denote abnormality in sperm heads and tails, respectively. Stars indicate the presence of immature germ at the gradient interface cells in the KO samples.

The distribution between pelleted and interfaced sperm after Percoll gradient centrifugation from 8-month-old $\mathrm{Arsa}^{-1-}$ mice was $20 \%$ and $80 \%$ of total sperm, respectively, values significantly different from those of the WT counterparts (Figure 11A). Although the majority of pelleted sperm from $\mathrm{Arsa}^{-/}$mice were motile, their progressive velocity was much reduced ( $~ 50 \%$ of the WT counterparts). Light microscopic analyses also revealed abnormal morphology of these sperm heads (red arrow head) including misshapen heads, heads of reduced sizes and heads detached from tails. Sperm tails showing $180^{\circ}$ folding towards the heads (black arrow) were also observed (Figure 11B). In the interfaced fraction, a higher number of sperm with the same abnormal morphology were observed. In addition, a number of immature round germ cells were present in the interfaced fraction. The percentages of these round germ cells (star) were variable and could be up to $60 \%$, such as that observed in Arsa KO mouse \#2 (Figure 11B).

\section{Discussion}

In this report, we demonstrated that SGG was co-localized with ARSA and the coenzyme, saposin B, in the lysosomes in the primary Sertoli cell cultures of 8-month-old WT 
animals (Figures 1 and 2). However, in Sertoli cells of age-matched Arsa null mice, SGG was accumulated not only in the distended lysosomes but also in the cytoplasm and the plasma membrane (Figure 2). The marked increase in SGG amounts in these Arsa null Sertoli cells was demonstrated by both immunofluorescence and quantitative ESI-MS/MS (Figures 2 and 3). Since Sertoli cells do not have enzymes in the biosynthesis pathway of SGG [1], the results indicated that the accumulated intracellular SGG were from apoptotic TGCs and residual bodies, which were phagocytosed by Sertoli cells. The accumulation of SGG together with the distention of lysosomes in $\mathrm{Arsa}^{-/}-$Sertoli cells is a typical feature of LSD, which can result in a number of pathogenic cascades [18]. The increase in oxidative stress has been described in other LSDs (e.g., Fabry, Gaucher, Nieman-Pick C1/C2 diseases) [31-34]. Although ROS at low amounts is beneficial for various physiological processes including the support of spermatogenesis $[35,36]$, ROS at high concentrations in the oxidative stress state will lead to oxidative damages to DNA, proteins and lipids [37-39]. With the apparent impairment of $\mathrm{Arsa}^{-/}$Sertoli cells ([17]; Figures 7 and 8), we therefore first determined relative levels of superoxide anion and $\mathrm{H}_{2} \mathrm{O}_{2}$ in these cells. Our results indeed indicated increased levels of superoxide anion and $\mathrm{H}_{2} \mathrm{O}_{2}$ in $\mathrm{Arsa}^{-/}$- Sertoli cells from mice both 5 months and 8 months of age, as compared with WT Sertoli cells from agematched mice (Figures 5 and 6). Our results corroborate the previous findings describing increased levels of ROS in induced pluripotent stem cells (iPSCs) generated from MLD patients (having Arsa mutations and the intracellular accumulation of sulfatides (SGG's analogues)) as well as their derived cells. Notably, all of these cells exhibit lysosomal distention due to the sulfatide accumulation [40], a result analogous to our observation in Sertoli cells of aging Arsa null Sertoli cells.

The production of superoxide anion occurs mainly during the mitochondrial electron transport chain $[41,42]$. Since lysosomes and mitochondria are closely associated with each other both physically and functionally, with cross-talk communication between the two organelles [43], the distention of lysosomes with aberrant activity in processing sulfated glycoconjugates in Arsa null Sertoli cells may cause their mitochondria to produce increased amounts of superoxide, as compared with WT Sertoli cells. In fact, the superoxide production was statistically higher in $\mathrm{Arsa}^{-/-}$Sertoli cells than in WT counterparts in 5-month-old animals. However, the corresponding comparison in 8-month-old $\mathrm{Arsa}^{-/-}$ and WT animals only showed a trend, but without a significant difference (Figure 5A). This disparity may be from substantial increases in ROS production due to aging [44], occurring in both WT and Arsa null mice. Specifically, the 2HE/DHE amount (reflecting superoxide level) in Sertoli cells from 8-month-old WT mice was 200 nmole/ $\mu$ mole, 3.6 times of the corresponding value from 5-month-old WT animals (i.e., $55 \mathrm{nmole} / \mu$ mole). This large increase owing to aging would diminish the sharp difference in the superoxide amounts in Sertoli cells, attributed to Sertoli lysosomal swelling in aging $\mathrm{Arsa}^{-/}{ }^{-}$mice.

Sertoli cells possess $\mathrm{SOD}$, which generates $\mathrm{H}_{2} \mathrm{O}_{2}$ from superoxide $\left[29\right.$,30]. $\mathrm{H}_{2} \mathrm{O}_{2}$ can be further processed into non-reactive products (e.g., water) by scavenger enzymes such as catalase and glutathione-dependent enzymes [29,30,45,46]. Notably, the levels of $\mathrm{H}_{2} \mathrm{O}_{2}$ in Sertoli cells from WT males both 5 months and 8 months of age were comparable (Figure 6), indicating that the increased amounts of superoxide due to aging could be effectively processed and WT Sertoli cells at both ages could survive and function at these baseline $\mathrm{H}_{2} \mathrm{O}_{2}$ amounts. Sertoli cells from 8-month-old WT mice are morphologically the same as those from younger males (our unpublished observations). In contrast, the levels of $\mathrm{H}_{2} \mathrm{O}_{2}$ in Sertoli cells from Arsa KO males were significantly higher than those in Sertoli cells from age-matched WT males at both 5 months and 8 months of age (Figure 6). These results suggest that the ROS scavenger enzymes of Sertoli cells in Arsa KO mice may not function well. It was possible that part of $\mathrm{H}_{2} \mathrm{O}_{2}$ produced in Arsa null Sertoli cells may have been converted to $\mathrm{OH}^{\bullet}$ radical via the Fenton reaction, catalyzed by $\mathrm{Fe}^{2+}[39,47]$. The highly reactive $\mathrm{OH}^{\bullet}$ would react instantaneously and irreversibly with biomolecules including DNA, proteins (including ROS scavenger enzymes) and lipids [37,39]. In particular, its reaction with polyunsaturated fatty acids (PUFA, known to be present in Sertoli cells [48,49]) 
would lead to lipid peroxidation and formation of lipid aldehydes, which would further form adducts with DNA and proteins [50], including those involved in the mitochondrial electron transport chain. The latter would result in further increase in ROS production [51]. These $\mathrm{OH}^{\bullet}$-induced molecular damages would accrue with time, and this may be the cause that Sertoli cells from 8-month-old Arsa null mice became smaller with nuclei dislocated towards the basement membrane, while Sertoli cells from 5-month-old KO males were still morphologically normal [17]. The high apoptosis rate of Sertoli cells from 8-month-old Arsa null males (Figure 7) may also reflect the oxidative damages occurring in vivo.

In the male reproductive system, ARSA activity is the highest in Sertoli cells [1]. Therefore, the increased ROS levels in Sertoli cells of Arsa null mice were not unexpected. In contrast, the finding that superoxide levels were also elevated in TGCs of Arsa KO mice (Figure 5B) needs an explanation on its mechanism. Since $\mathrm{H}_{2} \mathrm{O}_{2}$ can permeate the cell membranes [52], it could be speculated that a portion of newly formed $\mathrm{H}_{2} \mathrm{O}_{2}$ could exit Sertoli cells into the adluminal compartment and then enter developing TGCs residing in this space. Due to higher levels of $\mathrm{H}_{2} \mathrm{O}_{2}$ produced by Arsa null Sertoli cells, the entry of $\mathrm{H}_{2} \mathrm{O}_{2}$ into TGCs would be at higher rates in the $\mathrm{KO}$ animals. Formation of the $\mathrm{OH}^{\bullet}$ radical may then occur with a consequence of molecular and then cellular damages in an analogous manner to that postulated for Sertoli cells. In particular, TGCs are very enriched in PUFA-containing lipids [53,54], and therefore, lipid aldehydes could be formed following the reaction of these lipids with $\mathrm{OH}^{\bullet}$. As described for Sertoli cells above, this could also lead to the increased production of superoxide by mitochondria of Arsa null TGCs, as observed in our study (Figure 5). Accumulated molecular damages due to oxidative stress would lead to cellular impairment in due time, as evidenced by a high apoptosis rate of TGCs as well as the dislodgement of some TGCs from the seminiferous tubules into the epididymal lumen in 8-month-old Arsa KO mice [17]. The presence of TGCs in the epididymal lumen could have been one cause of higher levels of superoxide in the epididymis and these TGCs could have also released $\mathrm{H}_{2} \mathrm{O}_{2}$ into the surrounding area, resulting in higher amounts of this ROS in the epididymal lumen of aging $\mathrm{KO}$ mice (Figure 9A,B). While the majority of TGCs in aging Arsa KO males was still present in the seminiferous tubule epithelium, oxidative damages on their molecular components may have slowed down and/or induced aberrancy in their development into testicular sperm. Additional oxidative damages may have occurred during epididymal maturation of the sperm of aging Arsa $\mathrm{KO}$ mice because of higher levels of $\mathrm{H}_{2} \mathrm{O}_{2}$ but decreased levels of antioxidants in the epididymal lumen in these mice (Figure $9 \mathrm{~B}, \mathrm{C}$ ). Consequently, the decreases in the spermatogenesis rate (Supplemental Figure S6, [17]) and the increased numbers of sperm with abnormal morphology and immotility (Figure 11) were evident in aging Arsa null mice.

The intracellular accumulation of SGG in Sertoli cells of aging Arsa KO mice was associated not only with increased levels of ROS but also a decrease in cholesterol content in these cells (Figure 4). In Sertoli cells of WT mice, SGG existed mainly in the lysosome ready to be catabolized. In contrast, SGG was present in the lysosome as well as in the cytoplasmic vesicles and plasma membrane of Sertoli cells of aging Arsa KO mice (Figure 2). Since SGG is the lipid that endows rigidity to biomembranes [55], its presence on the plasma membrane of Arsa null Sertoli cells would have made this cell surface aberrantly ordered and perhaps physiologically unfavorable. Likewise, cholesterol is known to provide orderedness to biomembranes [56]. Therefore, a release of cholesterol from the plasma membrane, resulting in the decrease of cholesterol content, would be one avenue in adjusting the biophysical behavior of the Arsa null Sertoli plasma membrane towards normalcy.

In contrast to the SGG accumulation observed in Sertoli cells of aging Arsa $\mathrm{KO}$ mice, SGG amounts in sperm (Figure 10) and TGCs [17] in these mice were only $50 \%$ of the WT values. We have previously explained that this reduction is attributed to decreased activity of the enzymes, CGT and CST, in the biosynthesis pathway of SGG in TGCs [17], and our results herein revealing increases in superoxide anion and thus oxidative stress in these 
cells supported this postulation. The marked decrease in SGG levels would have caused reduced stability to the plasma membrane of Arsa null sperm. However, the levels of cholesterol sulfate, which could be synthesized in the epididymis [57,58], were significantly increased in Arsa null sperm (Figure 10). Since cholesterol sulfate [57] is known as a sperm plasma membrane stabilizer, its increase would allow the Arsa null sperm plasma membrane to regain its orderedness at least partly.

In summary, our studies herein demonstrated that the intracellular accumulation of SGG in Sertoli cells in $\mathrm{Arsa}^{-/-}$was likely the main cause of increased ROS production in these cells as well as TGCs, and subsequently the prolonged oxidative damages led to observed dysfunctions of Sertoli cells and subfertility in aging Arsa null mice [17]. Our study can serve as a model for an investigation of how oxidative stress of Sertoli cells can result in male infertility/subfertility.

\section{Conclusions}

Using Arsa null male mice as an experimental model, we reported herein that accumulation of SGG (seminolipid) in ARSA deficient Sertoli cells led to increases in ROS levels, and then molecular and cellular damages. The oxidative stress in these reproductive cells likely was the cause of the subsequent increases in ROS in TGCs and thus a decreased rate of spermatogenesis as well as formation of sperm with abnormal morphology and physiology.

Supplementary Materials: Table S1 and Figures S1-S8 as well as their legends are available online at figshare repository: https:/ / doi.org/10.6084/m9.figshare.13697122.v1.

Author Contributions: N.T.: providing concepts and directions of the study; N.T., D.B., K.F.F., M.A.B., K.K. and A.S.: designing experiments and providing protocols; K.K., A.S., W.K. and K.F.F.: performing the experiments; K.K., A.S., K.F.F., D.B., M.A.B. and N.T.: analyzing and interpreting the data; N.T., K.K., A.S. and D.B.: preparing the manuscript draft; N.T., K.K., A.S., D.B., K.F.F., M.A.B., and W.K.: proofreading and editing the manuscript, with N.T. overseeing the activities and together with K.K. finalizing the manuscript submission. All authors have read and agreed to the published version of the manuscript.

Funding: This work was supported by a grant from Canadian Institutes of Health Research (MOP 119438).

Institutional Review Board Statement: The use of mice (protocol 2568) was approved by the University of Ottawa Animal Care Committee, which endorses the use of ARRIVE checklists and guideline.

Informed Consent Statement: Not applicable.

Data Availability Statement: All data from this study are contained within this article and supplemental information.

Acknowledgments: We thank Terri Van Gulik for the manuscript preparation.

Conflicts of Interest: All authors declare that they have no conflicts of interest on the contents of this paper.

\section{References}

1. Tanphaichitr, N.; Kongmanas, K.; Faull, K.F.; Whitelegge, J.; Compostella, F.; Goto-Inoue, N.; Linton, J.J.; Doyle, B.; Oko, R.; Xu, H.; et al. Properties, metabolism and roles of sulfogalactosylglycerolipid in male reproduction. Prog. Lipid Res. 2018, $72,18-41$. [CrossRef] [PubMed]

2. Kongmanas, K.; Xu, H.; Yaghoubian, A.; Franchini, L.; Panza, L.; Ronchetti, F.; Faull, K.; Tanphaichitr, N. Quantification of seminolipid by LC-ESI-MS/MS-multiple reaction monitoring: Compensatory levels in $\mathrm{Cg}^{+/-}$mice. J. Lipid Res. 2010, 51, 3548-3558. [CrossRef]

3. Coetzee, T.; Fujita, N.; Dupree, J.; Shi, R.; Blight, A.; Suzuki, K.; Popko, B. Myelination in the absence of galactorcerebroside and sulfatide: Normal structure with abnormal function and regional instability. Cell 1996, 86, 209-219. [CrossRef]

4. Honke, K.; Hirahara, Y.; Dupree, J.; Suzuki, K.; Popko, B.; Fukushima, K.; Fukushima, J.; Nagasawa, T.; Yoshida, N.; Wada, Y.; et al. Paranodal junction formation and spermatogenesis require sulfoglycolipids. Proc. Natl. Acad. Sci. USA 2002, 99, 4227-4232. [CrossRef] 
5. Fujimoto, H.; Tadano-Aritomi, K.; Tokumasu, A.; Ito, K.; Hikita, T.; Suzuki, K.; Ishizuka, I. Requirement of seminolipid in spermatogenesis revealed by UDP-galactose:ceramide galactosyltransferase-deficient mice. J. Biol. Chem. 2000, 275, 22623-22626. [CrossRef]

6. White, D.; Weerachatyanukul, W.; Gadella, B.; Kamolvarin, N.; Attar, M.; Tanphaichitr, N. Role of sperm sulfogalactosylglycerolipid in mouse sperm-zona pellucida binding. Biol. Reprod. 2000, 63, 147-155. [CrossRef] [PubMed]

7. Weerachatyanukul, W.; Rattanachaiyanont, M.; Carmona, E.; Furimsky, A.; Mai, A.; Shoushtarian, A.; Sirichotiyakul, S.; Ballakier, H.; Leader, A.; Tanphaichitr, N. Sulfogalactosylglycerolipid is involved in human gamete interaction. Mol. Reprod. Dev. 2001, 60, 569-578. [CrossRef] [PubMed]

8. Bou Khalil, M.; Chakrabandhu, K.; Xu, H.; Weerachatyanukul, W.; Buhr, M.; Berger, T.; Carmona, E.; Vuong, N.; Kumarathasan, P.; Wong, P.T.; et al. Sperm capacitation induces an increase in lipid rafts having zona pellucida binding ability and containing sulfogalactosylglycerolipid. Dev. Biol. 2006, 290, 220-235. [CrossRef]

9. Weerachatyanukul, W.; Probodh, I.; Kongmanas, K.; Tanphaichiatr, N.; Johnston, L.J. Visualizing the localization of sulfoglycolipids in lipid raft domains in model membranes and sperm membrane extracts. Biochim. Biophys. Acta 2007, 1768, 299-310. [CrossRef]

10. Kongmanas, K.; Kruevaisayawan, H.; Saewu, A.; Sugeng, C.; Fernandes, J.; Souda, P.; Angel, J.B.; Faull, K.F.; Aitken, R.J.; Whitelegge, J.; et al. Proteomic characterization of pig sperm anterior head plasma membrane reveals roles of acrosomal proteins in ZP3 binding. J. Cell. Physiol. 2015, 230, 449-463. [CrossRef] [PubMed]

11. Gieselmann, V. Metachromatic Leukodystrophy. In Lysosomal Storage Disorders; Barranger, J.A., Cabrera-Salazar, M.A., Eds.; Springer: New York, NY, USA, 2007; pp. 285-306.

12. Matsuda, J.; Suzuki, K. Krabbe Disease (Globoid Cell Leukodystrophy). In Lysosomal Storage Disorders; Barranger, J.A., CabreraSalazar, M.A., Eds.; Springer: New York, NY, USA, 2007; pp. 269-283.

13. Rafi, M.A.; Rao, H.Z.; Luzi, P.; Curtis, M.T.; Wenger, D.A. Extended normal life after AAVrh10-mediated gene therapy in the mouse model of Krabbe disease. Mol. Ther. 2012, 20, 2031-2042. [CrossRef]

14. Luddi, A.; Strazza, M.; Carbone, M.; Moretti, E.; Costantino-Ceccarini, E. Galactosylceramidase deficiency causes sperm abnormalities in the mouse model of globoid cell leukodystrophy. Exp.Cell Res. 2005, 304, 59-68. [CrossRef]

15. Luddi, A.; Gori, M.; Crifasi, L.; Marrocco, C.; Belmonte, G.; Costantino-Ceccarini, E.; Piomboni, P. Impaired spermatogenesis in the twitcher mouse: A morphological evaluation from the seminiferous tubules to epididymal transit. Syst. Biol. Reprod. Med. 2017, 63, 77-85. [CrossRef]

16. Hess, B.; Saftig, P.; Hartmann, D.; Coenen, R.; Lullmann-Rauch, R.; Goebel, H.H.; Evers, M.; von Figura, K.; D’Hooge, R.; Nagel, G.; et al. Phenotype of arylsulfatse A-deficient mice: Relationship to human metachromatic leukodystrophy. Proc. Natl. Acad. Sci. USA 1996, 93, 14821-14826. [CrossRef] [PubMed]

17. Xu, H.; Kongmanas, K.; Kadunganattil, S.; Smith, C.E.; Rupar, T.; Goto-Inoue, N.; Hermo, L.; Faull, K.F.; Tanphaichitr, N. Arylsulfatase A deficiency causes seminolipid accumulation and a lysosomal storage disorder in Sertoli cells. J. Lipid Res. 2011, 52, 2187-2197. [CrossRef]

18. Vitner, E.B.; Platt, F.M.; Futerman, A.H. Common and uncommon pathogenic cascades in lysosomal storage diseases. J Biol.Chem. 2010, 285, 20423-20427. [CrossRef]

19. Saewu, A.; Kongmanas, K.; Raghupathy, R.; Netherton, J.; Kadunganattil, S.; Linton, J.J.; Chaisuriyong, W.; Faull, K.F.; Baker, M.A.; Tanphaichitr, N. Primary Sertoli Cell Cultures From Adult Mice Have Different Properties Compared With Those Derived From 20-Day-Old Animals. Endocrinology 2020, 161. [CrossRef]

20. Tanphaichitr, N.; Smith, J.; Kates, M. Levels of sulfogalactosylglycerolipid in capacitated motile and immotile mouse spermatozoa. Biochem. Cell Biol. 1990, 68, 528-535. [CrossRef] [PubMed]

21. Towbin, H.; Gordon, J. Immunoblotting and dot immunobinding-current status and outlook. J. Immunol. Meth. 1984, 72, 313-340. [CrossRef]

22. Kates, M. Technique of lipidology: Isolation, analysis and identification of lipids. In Laboratory Techniques in Biochemistry and Molecular Biology; Burdon, R.H., Ed.; Elsevier: New York, NY, USA, 1986; pp. 100-278.

23. Fazlollahi, F.; Kongmanas, K.; Tanphaichitr, N.; Mallen-St Clair, J.; Gopen, Q.; Faull, K.F.; Suh, J.D. Lipidomic profiling of sinus mucosa from patients with chronic rhinosinusitis. Clin. Transl. Sci. 2015, 8, 107-115. [CrossRef]

24. Franchini, L.; Panza, L.; Kongmanas, K.; Tanphaichitr, N.; Faull, K.F.; Ronchetti, F. An efficient and convenient synthesis of deuterium-labelled seminolipid isotopomers and their ESI-MS characterization. Chem. Phys. Lipids 2008, 152, 78-85. [CrossRef] [PubMed]

25. Laurindo, F.R.; Fernandes, D.C.; Santos, C.X. Assessment of superoxide production and NADPH oxidase activity by HPLC analysis of dihydroethidium oxidation products. Methods Enzymol. 2008, 441, 237-260. [CrossRef]

26. Burger, D.; Montezano, A.C.; Nishigaki, N.; He, Y.; Carter, A.; Touyz, R.M. Endothelial microparticle formation by angiotensin II is mediated via Ang II receptor type I/NADPH oxidase/ Rho kinase pathways targeted to lipid rafts. Arterioscler. Thromb. Vasc. Biol. 2011, 31, 1898-1907. [CrossRef]

27. Schenk, M.; Koppisetty, C.A.; Santos, D.C.; Carmona, E.; Bhatia, S.; Nyholm, P.G.; Tanphaichitr, N. Interaction of arylsulfatase-A (ASA) with its natural sulfoglycolipid substrates: A computational and site-directed mutagenesis study. Glycoconj. J. 2009, 26, 1029-1045. [CrossRef] 
28. Leonova, T.; Qi, X.; Bencosme, A.; Ponce, E.; Sun, Y.; Grabowski, G.A. Proteolytic processing patterns of prosaposin in insect and mammalian cells. J. Biol. Chem. 1996, 271, 17312-17320. [CrossRef]

29. Bauché, F.; Fouchard, M.H.; Jégou, B. Antioxidant system in rat testicular cells. FEBS Lett. 1994, 349, 392-396. [CrossRef]

30. Yoganathan, T.; Eskild, W.; Hansson, V. Investigation of detoxification capacity of rat testicular germ cells and Sertoli cells. Free Radic. Biol. Med. 1989, 7, 355-359. [CrossRef]

31. Donida, B.; Jacques, C.E.D.; Mescka, C.P.; Rodrigues, D.G.B.; Marchetti, D.P.; Ribas, G.; Giugliani, R.; Vargas, C.R. Oxidative damage and redox in Lysosomal Storage Disorders: Biochemical markers. Clin. Chim. Acta 2017, 466, 46-53. [CrossRef]

32. Mello, A.S.; da Silva Garcia, C.; de Souza Machado, F.; da Silva Medeiros, N.; Wohlenberg, M.F.; Marinho, J.P.; Dani, C.; Funchal, C.; Coelho, J.C. Oxidative stress parameters of Gaucher disease type I patients. Mol. Genet. Metab. Rep. 2015, 4, 1-5. [CrossRef] [PubMed]

33. Shen, J.S.; Meng, X.L.; Moore, D.F.; Quirk, J.M.; Shayman, J.A.; Schiffmann, R.; Kaneski, C.R. Globotriaosylceramide induces oxidative stress and up-regulates cell adhesion molecule expression in Fabry disease endothelial cells. Mol. Genet. Metab. 2008, 95, 163-168. [CrossRef] [PubMed]

34. Deganuto, M.; Pittis, M.G.; Pines, A.; Dominissini, S.; Kelley, M.R.; Garcia, R.; Quadrifoglio, F.; Bembi, B.; Tell, G. Altered intracellular redox status in Gaucher disease fibroblasts and impairment of adaptive response against oxidative stress. J. Cell. Physiol. 2007, 212, 223-235. [CrossRef]

35. Morimoto, H.; Iwata, K.; Ogonuki, N.; Inoue, K.; Atsuo, O.; Kanatsu-Shinohara, M.; Morimoto, T.; Yabe-Nishimura, C.; Shinohara, T. ROS are required for mouse spermatogonial stem cell self-renewal. Cell Stem Cell 2013, 12, 774-786. [CrossRef] [PubMed]

36. Fujii, J.; Imai, H. Redox reactions in mammalian spermatogenesis and the potential targets of reactive oxygen species under oxidative stress. Spermatogenesis 2014, 4, e979108. [CrossRef]

37. Cadet, J.; Wagner, J.R. DNA base damage by reactive oxygen species, oxidizing agents, and UV radiation. Cold Spring Harb. Perspect. Biol. 2013, 5, a012559. [CrossRef]

38. Ayala, A.; Muñoz, M.F.; Argüelles, S. Lipid peroxidation: Production, metabolism, and signaling mechanisms of malondialdehyde and 4-hydroxy-2-nonenal. Oxid. Med. Cell Longev. 2014, 2014, 360438. [CrossRef]

39. Halliwell, B.G.; John, M.C. Free Radicals in Biology and Medicine, 5th ed.; Oxford University Press: Oxford, UK, 2015.

40. Frati, G.; Luciani, M.; Meneghini, V.; De Cicco, S.; Ståhlman, M.; Blomqvist, M.; Grossi, S.; Filocamo, M.; Morena, F.; Menegon, A.; et al. Human iPSC-based models highlight defective glial and neuronal differentiation from neural progenitor cells in metachromatic leukodystrophy. Cell Death Dis. 2018, 9, 698. [CrossRef]

41. Valko, M.; Leibfritz, D.; Moncol, J.; Cronin, M.T.; Mazur, M.; Telser, J. Free radicals and antioxidants in normal physiological functions and human disease. Int. J. Biochem. Cell Biol. 2007, 39, 44-84. [CrossRef]

42. Villaverde, A.; Netherton, J.; Baker, M.A. From Past to Present: The Link Between Reactive Oxygen Species in Sperm and Male Infertility. Antioxidants 2019, 8, 616. [CrossRef]

43. Todkar, K.; Ilamathi, H.S.; Germain, M. Mitochondria and Lysosomes: Discovering Bonds. Front. Cell Dev. Biol. $2017,5,106$. [CrossRef] [PubMed]

44. Amaral, S.; Amaral, A.; Ramalho-Santos, J. Aging and male reproductive function: A mitochondrial perspective. Front. Biosci. 2013, 5, 181-197. [CrossRef] [PubMed]

45. Fujii, J.; Iuchi, Y.; Matsuki, S.; Ishii, T. Cooperative function of antioxidant and redox systems against oxidative stress in male reproductive tissues. Asian J. Androl. 2003, 5, 231-242. [PubMed]

46. Pasquali, M.A.; Gelain, D.P.; Zanotto-Filho, A.; de Souza, L.F.; de Oliveira, R.B.; Klamt, F.; Moreira, J.C. Retinol and retinoic acid modulate catalase activity in Sertoli cells by distinct and gene expression-independent mechanisms. Toxicol. Vitr. 2008, 22, 1177-1183. [CrossRef] [PubMed]

47. Nathan, C.; Ding, A. SnapShot: Reactive Oxygen Intermediates (ROI). Cell 2010, 140, 951.e1-951.e2. [CrossRef]

48. Vallés, A.S.; Aveldaño, M.I.; Furland, N.E. Altered lipid homeostasis in Sertoli cells stressed by mild hyperthermia. PLoS ONE 2014, 9, e91127. [CrossRef]

49. Koeberle, A.; Shindou, H.; Harayama, T.; Shimizu, T. Role of lysophosphatidic acid acyltransferase 3 for the supply of highly polyunsaturated fatty acids in TM4 Sertoli cells. FASEB J. 2010, 24, 4929-4938. [CrossRef]

50. Hauck, A.K.; Bernlohr, D.A. Oxidative stress and lipotoxicity. J. Lipid Res. 2016, 57, 1976-1986. [CrossRef]

51. Aitken, R.J.; Baker, M.A. The Role of Genetics and Oxidative Stress in the Etiology of Male Infertility-A Unifying Hypothesis? Front. Endocrinol. 2020, 11, 581838. [CrossRef]

52. Laporte, A.; Lortz, S.; Schaal, C.; Lenzen, S.; Elsner, M. Hydrogen peroxide permeability of cellular membranes in insulinproducing cells. Biochim. Biophys. Acta Biomembr. 2020, 1862, 183096. [CrossRef]

53. Retterstol, K.; Tran, T.N.; Haugen, T.B.; Christophersen, B.O. Metabolism of very long chain polyunsaturated fatty acids in isolated rat germ cells. Lipids 2001, 36, 601-606. [CrossRef] [PubMed]

54. Oresti, G.M.; Reyes, J.G.; Luquez, J.M.; Osses, N.; Furland, N.E.; Aveldaño, M.I. Differentiation-related changes in lipid classes with long-chain and very long-chain polyenoic fatty acids in rat spermatogenic cells. J. Lipid Res. 2010, 51, 2909-2921. [CrossRef]

55. Attar, M.; Kates, M.; Bou Khalil, M.; Carrier, D.; Wong, P.T.T.; Tanphaichitr, N. A Fourier-transform infrared study of the interaction between germ-cell specific sulfogalactosylglycerolipid and dimyristoylglycerophosphocholine. Chem. Phys. Lipids 2000, 106, 101-114. [CrossRef] 
56. Bloom, M.; Evans, E.; Mouritsen, O.G. Physical properties of the fluid lipid-bilayer component of cell membranes: A perspective. Quart. Rev. Biophys. 1991, 24, 293-397. [CrossRef] [PubMed]

57. Roberts, K.D. Sterol sulfates in the epididymis; synthesis and possible function in the reproductive process. J. Steroid Biochem. 1987, 27, 337-341. [CrossRef]

58. Zimmer, B.; Tenbusch, L.; Klymiuk, M.C.; Dezhkam, Y.; Schuler, G. Sulfation pathways: Expression of SULT2A1, SULT2B1 and HSD3B1 in the porcine testis and epididymis. J. Mol. Endocrinol. 2018, 61, M41-M55. [CrossRef] [PubMed] 